\title{
Poblamiento y asentamientos rurales andalusíes: análisis del paisaje y caracterización territorial de un valle del 'amal Šaqūra (siglos VIII-XII)*
}

\author{
Population and Andalusi Rural Settlement: Landscape Analysis and Territorial \\ Characterization of a Valley of the 'amal Šaqüra $\left(8^{\text {th }}-12^{\text {th }}\right.$ centuries $)$
}

\author{
Santiago Quesada-García \\ Universidad de Sevilla \\ ORCID iD: https://orcid.org/0000-0002-6108-459X
}

\begin{abstract}
Resumen
En el valle de los ríos Trujala, Hornos y Guadalimar en la Sierra de Segura, al noreste de la provincia de Jaén, se conserva un articulado sistema de estructuras medievales que configuran un paisaje. Para orientarse en él, hace falta un mapa que represente con precisión los elementos que intervienen en su conformación. El objetivo de este trabajo es revelar esos puntos y trazar una cartografía que sirva para comprender e interpretar el palimpsesto del paisaje. Con ese fin se realiza una prospección intensiva del territorio que documente los vestigios existentes, elaborando posteriormente un modelo de evaluación basado en Sistemas de Información Geográfica. Este proceso permite cuantificar variables, obtener datos estadísticamente relevantes y clasificar la información obtenida en los lugares donde se conserva alguna preexistencia medieval. Los resultados suministran parámetros útiles en la lectura analítica del paisaje, aportan conocimiento cuantitativo sobre factores que intervienen en los emplazamientos y permiten la determinación de sus patrones de asentamiento. También revelan el modo de ocupación en un territorio perteneciente al 'amal Šaqūra como reflejo de la organización campesina en el mundo rural y el rol antropizador que han tenido en la configuración del paisaje los poblamientos asociados a unas estructuras construidas en tapia durante el siglo XII.
\end{abstract}

Palabras clave: al-Andalus; paisaje rural; poblamiento medieval; asentamientos andalusíes; caracterización territorial; Sierra de Segura (Jaén).

\begin{abstract}
In the valley of the Trujala, Hornos and Guadalimar rivers in the Sierra de Segura, northeast of the province of Jaén (Spain), is an articulated system of preserved Andalusi structures that configure a landscape. To orient in a landscape, one needs a map that accurately represents the elements involved in its formation. The objective of this work is to reveal these points and to draw a chart that serves to understand and read into the palimpsest of the landscape. To achieve this, an intensive prospecting of the territory is carried out to document the existing remains and an evaluation model based on Geographic Information Systems is elaborated. This process allowed for quantifying variables, obtaining statistically relevant data and classifying the information obtained in places where there is some Andalusi preexistence. The results supply useful parameters in the analytical reading of the landscape, provide quantitative knowledge about factors that connect the sites, and allow for the determination of settlement patterns. The results also reveal the mode of occupation in a territory —-the ancient 'amal $\check{S} a q \bar{u} r a$ - as a reflection of the Andalusi organization in the rural world and the anthropic role that these settlements, which are associated with structures built of rammed-earth during the $12^{\text {th }}$ century, have had in the landscape's configuration.
\end{abstract}

Key words: al-Andalus; Rural Landscape; Medieval Population; Andalusi Settlements; Territorial; Characterization; Sierra de Segura (Jaén).

Cómo citar / Citation: Quesada-García, Santiago, "Poblamiento y asentamientos rurales andalusíes: análisis del paisaje y caracterización territorial de un valle del 'amal Šaqüra (siglos VIII-XII)”, Al-Qanțara, 42, 2 (2021), e17. doi: https://doi.org/10.3989/ alqantara.2021.014.

Recibido: 15/06/2020; Aceptado: 18/05/2021; Publicado: 16/12/2021

* Este trabajo ha sido posible gracias a la financiación del proyecto de investigación $\mathrm{I}+\mathrm{D}+\mathrm{i}$ : «El sistema de torres de origen medieval islámico en Segura de la Sierra, implantación, técnicas constructivas y restauración del tapial» (HAR2014-53866-R) del Plan Estatal de Investigación Científica y Técnica y de Innovación 2013-2016 y del proyecto de investigación competitivo: «La arquitectura de la defensa como articulación del territorio y elaboración del paisaje: las torres almohades de la Sierra de Segura» (130-10254) financiado en 2018 por la Secretaría General de Política de Defensa. 


\section{Introducción}

Hay excelentes estudios que afrontan los diferentes modos de poblamiento de al-Andalus y analizan su organización socio-económica, productiva y fiscal, así como su problemática territorial. No obstante, quedan muchos lugares, aspectos y matices por conocer en su territorio rural porque todavía no se disponen de fuentes documentales suficientes, no se ha pasado de un primer nivel de reconocimiento o hay problemas de índole metodológica cuando no hay datos arqueológicos fiables, cuando los restos conservados se estudian como objetos aislados - en ocasiones de forma literalmente microscópica- o cuando no hay conexión entre los necesarios estudios interdisciplinares ${ }^{1}$. Estas limitaciones hacen que sea complicado caracterizar los asentamientos rurales andalusíes existentes y que haya muchas preguntas sobre cómo eran sus criterios de implantación, cuántos elementos las formaban y cuáles eran sus funciones.

El terreno donde se implantan estos establecimientos medievales está constituido por estratificaciones sucesivas que guardan la memoria de las marcas de su fundación, por lo que todavía es posible abordar aspectos poco analizados de estos asentamientos ${ }^{2}$. El abundante número de ellos que aún se conservan en la Península Ibérica proporciona una inapreciable oportunidad que permite su revisión y relectura. Por otro lado, la diversidad de situaciones existentes en el mundo rural, el silencio de las fuentes documentales y la dificultad de hacer excavaciones arqueológicas, hacen imprescindible encontrar nuevas fuentes de información que permitan avanzar en el conocimiento de las relaciones espaciales entre hábitat y territorio, la jerarquización de las redes de establecimientos y la organización del poblamiento rural en al-Andalus. El estudio del paisaje junto con la arqueología de la arquitectura, con el apoyo de disciplinas como la palinología o la toponimia, entre otras, puede suministrar esas nuevas fuentes y complementar las existentes ${ }^{3}$. Un análisis descriptivo del paisaje permite acercarse, desde diversas perspectivas y métodos, a los modos de ocupación de los poblamientos revelando sus trazas, conexiones, características y relaciones con el medio natural en el que se insertan.

\footnotetext{
Pérez, "Problemas metodológicos".

2 Muratori, Civiltà e Territorio.

3 Barker, "L'archeologia del paesaggio", pp. 7-30; Kirchner y Navarro, “Objetivos, métodos y prácticas”, pp. 159-182.
}

La morfología y condiciones de los emplazamientos rurales andalusíes han sido referidas en las últimas décadas por numerosos autores, siendo descritas de modo muy exhaustivo y riguroso. La cuestión es cómo se pueden calibrar los elementos que se usan para describir el paisaje, cómo obtener datos cuantificables que contengan información útil que pueda ser comparada y así poder progresar en el discernimiento de una realidad histórica y territorial aún no suficientemente aclarada.

El examen detallado de las diferentes variables geo-morfológicas que aparecen en los establecimientos rurales de al-Andalus aporta parámetros, objetivamente contrastables, que revelan algunos rasgos del carácter de esos sitios y es una práctica eficaz que aumenta la información y el conocimiento histórico proveniente de fuentes documentales y registros arqueológicos. El estado de la investigación, en lo que respecta a la problemática expuesta, es una de las razones que avalan el interés de este trabajo, ya que en él se escruta y evalúa un paisaje con numerosos vestigios andalusíes desde una perspectiva poco explorada hasta el momento, con un procedimiento que aborda el estudio de sus formas de ocupación con Sistemas de Información Geográfica (SIG) que permiten obtener datos y nuevas fuentes de información.

El paisaje hacia el que dirige su mirada este estudio revela la existencia de un rico poblamiento rural articulado por un sistema de asentamientos de diferente escala y naturaleza. Un paisaje definido por una serie de estructuras construidas en tapia en el siglo XII y cuyo fondo es el marco natural del valle formado por los ríos Trujala, Hornos y Guadalimar. Un territorio que perteneció al 'amal Šaqūra, antigua amelía o distrito andalusí cuyo ámbito de influencia controlaba las cuencas altas de los ríos Segura, Guadalimar y Guadalquivir, abarcando el noreste de la provincia de Jaén y el suroeste de la provincia de Albacete (Figura 1). El estado de conservación de las preexistencias ha permitido su documentación y descripción con amplio detalle en anteriores etapas de la investigación ${ }^{4}$.

El objetivo de esta fase es extraer, analizar y ordenar los parámetros presentes en el entorno ocupado por cada una de las estructuras medievales, obteniendo datos que sirvan para revelar

$4 \quad$ El trabajo de nuestro equipo sobre estas estructuras medievales en tapia comenzó en el año 2003 y aún continúa. Quesada-García, El sistema de torres, pp.19-22. 


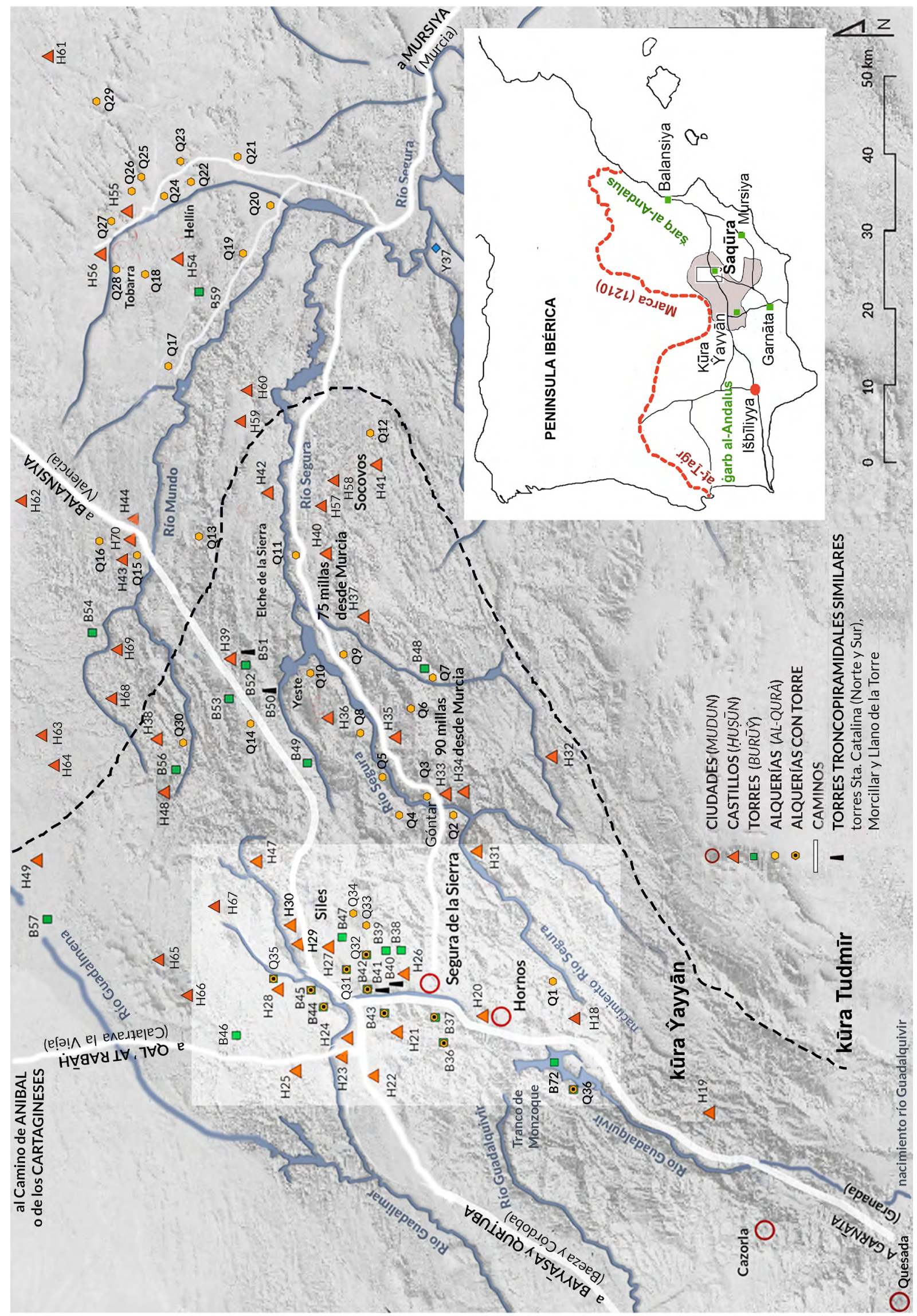


Fig. 1. Localización del ámbito de estudio dentro de la kūra Ğayyān y distribución de asentamientos andalusíes de los que aún quedan vestigios en los territorios del 'amal Šaqūra y comarcas limítrofes. Fuente: elaboración propia.

ḤUȘŪN: H18. Peñasmugo (Santiago-Pontones) H19. Castellón del Moro (Cazorla) H20. Hornos H21. Espinareda H22. Peñolite (Puente Génave) H23. Bujalamé (La Puerta de Segura) H24. El Castillo (La Puerta de Segura) H25. Matamoros (Puente Génave) H26. Segura de la Sierra H27. Morles (Siles) H28. La Yedra (Torres de Albánchez) H29. Peñafleita (Siles) H30. Tasca (Siles) H31. Aldea de Miller (Santiago-Pontones) H32. Taibilla (Nerpio) H33. Góntar (Yeste) H34. Castillico de Góntar (Yeste) H35. Graya (Yeste) H36. Yeste H37. Iznar (Letur) H38. Vegallera (Molinicos) H39. Molinicos H40. Letur H41. Socovos H42. Vicorto (Elche de la Sierra), H43. La Yedra (Ayna) H44. Híjar (Liétor) H47. Cotillas H48. Riópar Viejo (Riópar) H49. Alcaraz H54. Hellín H55. Sierra (Tobarra) H56. Tobarra H57. Abejuela (Letur) H58. Férez H59. Gutta (Elche de la Sierra) H60. Bueycorto (Elche de la Sierra) H61. Ontur H62. Alcadozo H63. Alcázar H64. Cortes (Alcaraz) H65. Povedilla H66. Villa Palacios H67. Villaverde de Guadalimar H68. Paterna del Madera H69. Bogarra H70. Híjar (Lietor). Y37. Villa Vieja (Calasparra).

BURŪŶ: B36. Altamira (Segura de la Sierra) B37. Gutamarta (Segura de la Sierra) B38. Torre del Agua (Segura de la Sierra) B39. Torre de Góntar (Segura de la Sierra) B40. Torre Sur Sta. Catalina (Orcera) B41. Torre Norte Sta. Catalina (Orcera) B42. Torre Aguadero Sta. Catalina (Orcera) B43. La Torre (Segura de la Sierra) B44. El Cardete (Benatae) B45. Fuente de la Torre (Benatae) B46. Torre de la Laguna (Génave) B47. Puente Honda (Siles) B48. Torre de Vizcable (Nerpio) B49. Moropeche (Yeste) B50. Llano de la Torre (Yeste) B51. Morcillar (Molinicos) B52. Cortijo León (Molinicos) B53. Torre-Pedro (Molinicos) B54. Haches (Bogarra) B56. Lugar Nuevo (Riópar) B57. Gorgojí (Alcaraz) B59. Isso (Hellín) B71. Mata (Caravaca de la Cruz) B72. Bujarcáiz (Hornos).

QURÀ: Q1. Las Gorgollitas (Santiago-Pontones) Q2. Góntar (Yeste) Q3. Alcantarilla (Yeste) Q4. Arguellite (Yeste) Q5. Boche (Yeste) Q6. Yetas (Nerpio) Q7. Vizcable (Nerpio/Yeste) Q8. Paúles (Yeste) Q9. Sujayar (Yeste) Q10. Jartos (Yeste) Q11. Almazarán (Letur) Q12. Tazona (Socovos) Q13. Peñarrubia (Elche de la Sierra) Q14. Raspílla (Yeste) Q15. Alcadima (Lietor) Q16. Moriscote (Ayna) Q17. Talave (Lietor) Q18. Abenuj (Tobarra) Q19. Agra (Hellín) Q20. Azaraque (Hellín) Q21.Minateda (Hellín) Q22. Vilches (Hellín) Q23. Puchea (Hellín) Q24. Cueva de Ubacar (Hellín) Q25. Alborajico (Tobarra) Q26. Alboraj (Tobarra) Q27. Aljube (Tobarra) Q28. Polope (Tobarra) Q29. Albatana Q30. Molinos (Molinicos) Q31. Benatae Q32. Orcera Q33. La Hueta (Orcera) Q34. Linarejos (Orcera) Q35. Torres de Albanchez Q36. Bujaraiza (Hornos).

patrones en sus formas de implantación y proponer una caracterización que facilite la compresión de los factores que han condicionado su distribución territorial. Los resultados alcanzados aportan un conocimiento cuantitativo sobre variables que intervienen en cada uno de los lugares y facilitan pautas que pueden ser utilizadas para el estudio, comparación e interpretación de otros paisajes rurales de al-Andalus.

\section{La memoria del paisaje del 'amal Šaqūra}

El territorio de las dependencias de Šaqūra ocupaba un amplio macizo montañoso localizado en la cordillera Prebética formada por las sierras de Segura, Cazorla, Las Villas, Alcaraz, El Pozo, Taibilla, Castril y La Sagra. Son parajes con múltiples paisajes, poblados por un variado paisanaje que habita en diversos países asentados en abruptas elevaciones o en terrenos ondulados y suaves. Las comarcas serranas de Segura presentan un clima mediterráneo continental de montaña con fuertes contrastes matizados por la altitud. La vegetación más abundante está formada por diferentes tipos de pinares; el más común es el pino carrasco, aunque el árbol emblemático es el pino salgareño o pino blanco (pinus nigra salzmannii) que crece por encima de los $1400 \mathrm{~m}$. En las cotas bajas, cuando no hay olivar, crece el bosque mediterráneo con encinas, robles, madroños, quejigos y arces. Es un territorio donde la explotación de la madera ha sido históricamente su principal recurso productivo junto con la ganadería y el pastoreo. Los estudios palinológicos indican que la acción antrópica ha sido determinante en la conformación de la vegetación del bosque altimontano mediterráneo de la zona ${ }^{5}$. Los registros polínicos también señalan la existencia de extensas zonas de pastizales en cotas altas de la Sierra, lo que demostraría que la trashumancia estacional ha prevalecido como actividad humana en esta comarca desde el II milenio a.e.c. hasta fechas recientes, confirmando la descripción del geógrafo Maḥallī sobre la abundancia de pastos en esta tierra ${ }^{6}$.

Según Lombard, entre los siglos VIII y XI, al-Andalus era de los pocos territorios que se autoabastecía de madera con la producción de los bosques de Tortosa y Segura ${ }^{7}$. La red fluvial era la infraestructura soporte para transportar la principal riqueza del territorio segureño. Al-Idrīsī indica que ğabal $\breve{S} a q u \bar{r} a^{8}$ es el lugar desde don-

Carrión, "Pastoreo y vulnerabilidad", pp. 7-22.

Aḥmad b. 'Alī Maḥallī, Tuḥfat al-mulūk, trad. Fagnan, Extraits, p. 143.

Lombard, "Un problème cartographié”, pp. 241-248.

Con la denominación ğabal Šaqūra se refieren, tanto al-Idrīsī como al-Zuhrī, al conjunto de montañas que configuran las actuales Sierra de Segura (Jaén) y Sierra del Segura (Albacete), no al monte singular que aloja a la ciudad. 
de parten al-Nahr al-Kabīr (río Guadalquivir) y al-Nahr al-Abyad (río Blanco, actual Segura) ${ }^{9}$ que discurre hacia la vega de Murcia y por donde, según al-Zuhrī, se conducían las maderas al Mediterráneo «en un trayecto de siete días» ${ }^{10}$. Hacia la vertiente atlántica se transportaban por el río Guadalimar hasta que éste desembocaba en el Guadalquivir, ya que no era posible hacerlo directamente en el alto Guadalquivir porque sus aguas desaparecían bajo tierra más de cien marğa' (aprox. dos kilómetros) a la altura del Tranco de Monzoque ${ }^{11}$.

El nombre árabe de Šaqūra deriva del latín secūra, un étimo que se aplicaría al lugar por ser un sitio protegido según Pocklington ${ }^{12}$. La arqueóloga y epigrafista A. Canto sostiene que durante los siglos III-II a.e.c., se controlaban desde aquí las calzadas que unían Hispalis e Iliberis con el levante peninsular e incluso que fue escenario de batallas en la Segunda Guerra Púnica ${ }^{13}$. Existen evidencias palinológicas de actividades agrícolas incipientes en cotas por encima de los 1320 m s.n.m. (La Laguna de Siles) a partir del año 550 d.e.c. ${ }^{14}$, por lo que es posible que, tal y como ocurrió en otras zonas $^{15}$, tras la fractura del ordenamiento romano los habitantes abandonaran los emplazamientos bajos por otros situados en lugares altos con el objetivo de refugiarse de peligros, abandonar las relaciones con el poder dominante o dejar de pagar tributos, dedicándose al aprovechamiento intensivo del bosque y otros recursos productivos.

9 Al-Idrīsī, Uns al-muhağ, pp. 277-278. Contemporáneamente, al-Zuhrī denomina al río Segura como wādī Tudmīr, Tandāyir o Țād(i) rū. Al-Zuhrī, Kitāb al-Ğa rāfiyya, parágrafo 254 y 256, pp. 208-209. Pocklington indica que esta última denominación proviene del topónimo latino Tader. Pocklington, "Toponimia ibérica", p. 128

10 Al-Zuhrī, Kitāb al-Ǧa rāfiyya, parágrafo 255, p. 209. Para este trabajo se ha realizado una traducción directa del árabe por parte de nuestro equipo de investigación a partir de la edición crítica de los manuscritos realizada por M. Hadj-Sadok.

11 Al-Zuhrī lo describe así: «Este río (Guadalquivir) sale del nacimiento pequeño, y se va haciendo grande con la afluencia de ríos y arroyos, y discurre sobre el terreno a lo largo de 10 parasangas (...) hasta que llega a las piedras denominadas hăgar al-mās en el lugar conocido como al-Qaštâr . Entonces se lo traga la tierra y se hunde hasta que no queda nada visible de él, una distancia de 100 marğa '. Por eso no se puede conducir madera sobre él como se hace sobre el río llamado wādī al-Ahmar (río Guadalimar)». Al-Zuhrī, Kitāb al-Ǧa rāfiyya, parágrafo 253, p. 209.

12 Pocklington, “Toponimia ibérica”, p. 128.

13 Canto, "Ilorci, Scipionis rogus (Plinio, NH III, 9)", pp. 154-157.

14 Carrión, "Pastoreo y vulnerabilidad", p. 14.

15 Quesada, "El poblamiento medieval", pp. 166-167.
Fuentes árabes medievales mencionan varios emplazamientos en altura como Šaqūra ${ }^{16}(1120$ m s.n.m.) o Furnus (894 m s.n.m.), actual Hornos, nombre también de origen latino o romance. Algunos autores indican que la función de este tipo de asentamientos era el control de acceso al interior de las sierras, donde se localizaban la madera y las fuentes de abastecimiento de las poblaciones ${ }^{17}$. Ibn Hayyān, cuando hace referencia a la fitna en la cuenca del río Segura, indica una fuerte presencia de población rūm (cristiana) a final del siglo IX; por éste y otros motivos hay investigadores que mantienen que esos sitios eran encastillamientos de esa comunidad no musulmana $^{18}$. La presencia de estos habitantes en la comarca durante la Alta Edad Media, junto con la administración posterior a la reconquista cristiana por la Encomienda de la Orden de Santiago, podría justificar la escasez de topónimos árabes entre los poblamientos de la zona.

Sin embargo, es posible encontrar nombres de probable origen semítico en poblaciones que, además, tienen una implantación diferente a la arquetípica disposición castral medieval del caserío rodeando una fortaleza. Uno de ellos es Benatae (842 m s.n.m.), topónimo de una población situada a pocos kilómetros al norte de Segura de la Sierra. Su asentamiento no se ubica en la cima de la montaña o en torno a un castillo sino en la cuenca de una depresión, sobre una meseta más cercana al terreno por donde discurre el río Guadalimar que a las cumbres de las montañas que lo rodean (Figura 2). Oliver Asín propone que la etimología del topónimo de Benatae podría ser Banū Tayy', manteniendo que dicho lugar fue una de las residencias de la tribu Tayy'19. Una observación que hace a partir de una aportación de E. Terés, que dice que un núcleo del linaje de esa tribu yemení de qahtāniées - establecida en el sur de Murcia, Baza y Cúllar- también debió de tener su residencia en

16 Šaqūra es citada como hiṣnn por Yāqūt (s. XII), Ibn Sa īìd (s. XIII) y Abū l-Fidā' (s. XIV). Como madīna por al-Zuhrī (s. XII) y al-Himyarī (s. XV). Aguirre y Jiménez, Introducción, pp. 44-45. Al-Idrīsī (s. XII) indica que Šaqūra es un ḥiṣn comparable a una madīna. Al-Idrīsī, Uns al-muhağ, p. 278.

17 Salvatierra y Visedo, "Segura”, pp. 139.

18 La denominación del río Segura como wādī Tandāyir, todavía en el siglo XII, ha llevado a algunos investigadores a considerar la existencia de una importante población rūm o mozárabe en la comarca. Frey, "La percepción del territorio", pp. 24-25. Respecto al encastillamiento, véase: Torres Balbás, Ciudades hispano-musulmanas, p. 195; Acién, "De nuevo sobre la fortificación", pp. 60-61.

19 Oliver, "En torno a los orígenes de Castilla", p. 341. 

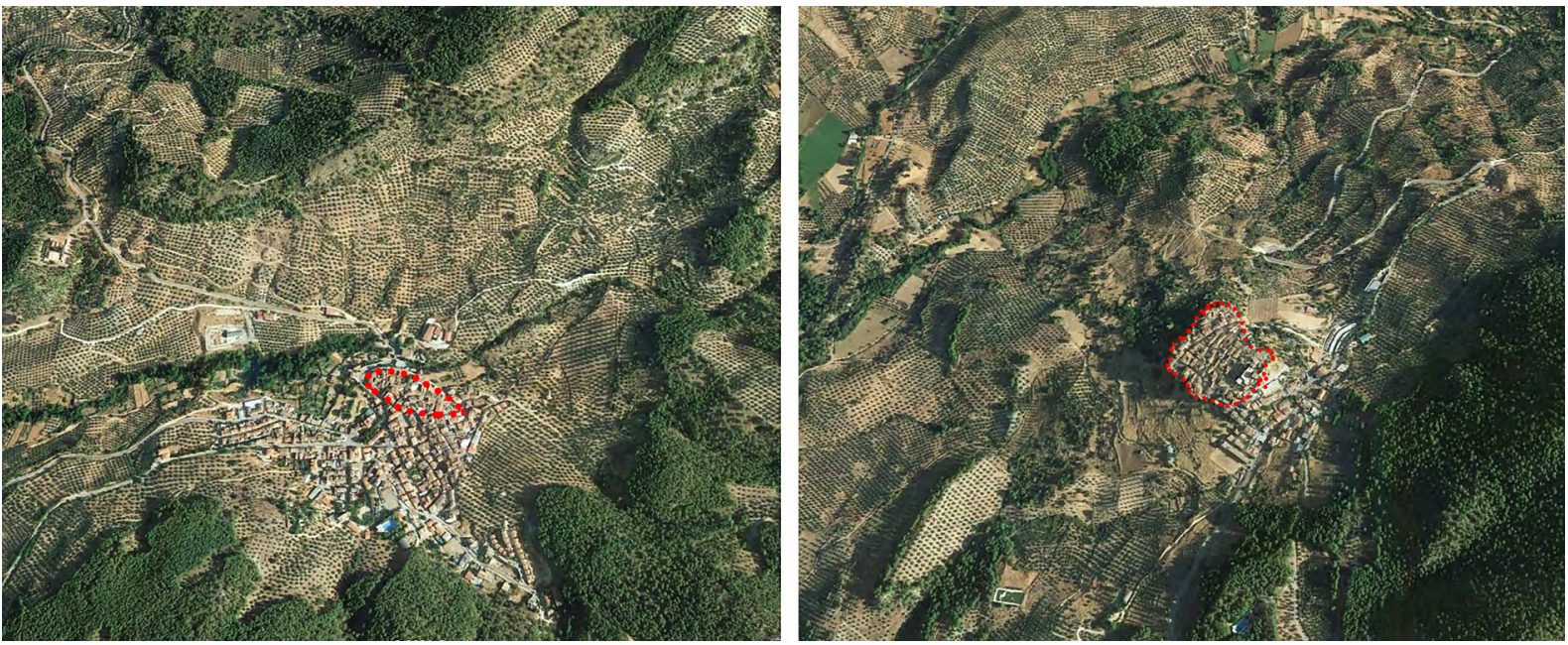

Fig. 2. Izquierda: ortofotografía de Benatae. Derecha: ortofotografía de Hornos. Dos tipos de implantación medieval diferentes. El primer asentamiento, en el que se ha señalado el núcleo inicial, se implanta en la cuenca de una depresión, cercana a tierras de labranza y al río Guadalimar. El segundo, en la cima de un risco con el caserío rodeando al castillo. Fuente: Google Earth y elaboración propia.

otros territorios de Ǧayyān (Jaén), donde vivían los Maysara y Qahțaba, tribus que contribuyeron activamente a la llegada de 'Abd al-Rahmān al-Dāhil a la Península ${ }^{20}$. Terés también recoge una información que da al-Maqqarī, cuando menciona al kātib y poeta Ibn Abī l-Ḩișāl, donde dice que la mayor parte de los habitantes de las comarcas de Segura se remontan a los Gāfiq, tribu árabe que, según el arabista español, desciende del linaje de 'Adnān ${ }^{21}$. Ibn Abī l-Hुișā ${ }^{22}$ nació en la alquería de Furgalìt o Fargalìt, cuyos habitantes, según las crónicas, eran los primeros que regaban con el agua del río Tandāyir (Segura $)^{23}$. Esa población, origen de varios literatos

20 Terés, "Linajes árabes en al-Andalus (conclusión)", pp. 344-345. Diversas crónicas árabes narran que 'Abd al-Raḥmān I estuvo por las tierras de Segura persiguiendo y combatiendo al bandido Hafila, que se había unido al sublevado Abū l-Aswad, siendo derrotados ambos junto al río Guadalimar. Aguirre y Jiménez, Introducción, p. 134. Cabe proponer la hipótesis de que el emir omeya podría haber recompensado con tierras en esta comarca a las familias qahtānies que lo apoyaron con el fin de poder controlar no solo a muladíes y rūmies, sino también a 'adnanies contrarios, que también se habían establecido por tierras segureñas.

${ }_{21}$ Terés, "Linajes árabes en al-Andalus ( $1^{\mathrm{a}}$ parte)", p. 111.

22 Se trata de Muhammad Ibn Abī l-Hișāal, un secretario ( $k a \bar{a} t i b)$ nacido en 465/1072 y muerto en Córdoba en 540/1146. Navarro, "Fortificaciones y asentamientos andalusíes", p. 224. Esta autora identifica Fargalīt con la aldea de Arguellite (t.m. de Yeste). Sin embargo, esta población, a diferencia de Las Gorgollitas, no se encuentra cerca del río Segura, ni de su nacimiento.

${ }^{23}$ «Au sud de la montagne coule la rivière nommée Tendàber qui se dirige vers Murcie et son territoire (...) sa source au lieu dit Feddj Yâkoûr (...) La première bourgade qu'il arrose est celle de Forghalît». Aḥmad b. 'Alī al-Maḥallī, Tuhfat al-mulūk, trad. Fagnan, Extraits, p. 144. y juristas andalusíes, se ha identificado con Las Gorgollitas (1320 m s.n.m.). Una aldea localizada en el municipio de Santiago-Pontones, en las tierras altas de la vertiente oriental de la Sierra, en un lugar con una abrupta pendiente, colonizado por un sistema de bancales con cultivos.

De confirmarse con registros arqueológicos las noticias que indican la presencia en la Sierra de Segura de árabes del norte y de yemeníes - Ġāifiq y Țayy' —, podría significar que la repoblación en las tierras serranas comenzó en el temprano siglo VIII y que serían estos grupos poblacionales los que podrían haber comenzado a introducir - en terrenos poco aptos y con tierra escasamente provechosa - espacios irrigados destinados a la agricultura intensiva como un nuevo recurso productivo que se añadiría a los ya existentes de la madera, la ganadería y el pastoreo. Hay que mencionar que, antes del advenimiento del islam, la mayoría de la población de la Península Arábiga estaba compuesta por pastores nómadas, salvo en las tierras altas del Yemen que estaban habitadas por agricultores sedentarios. Estos clanes tribales tendrían un saber sobre la distribución del agua, el aprovechamiento de la tierra y la organización del espacio agrario con ancestrales patrones de asentamiento asociados a ese conocimiento que, posiblemente, pondrían en práctica en sus nuevos establecimientos de la Península Ibérica.

Durante el gobierno de al-Hakam II, la cora de Jaén era una de las principales de al-Andalus ${ }^{24}$.

\footnotetext{
$24 \quad$ Aguirre y Jiménez, Introducción, p. 168.
} 
Según indica al-Wațāț en su Manāhiğ al-fikar ${ }^{25}$, la kūra de Ğayyān estaba dividida en quince distritos, uno de los cuales era el 'amal Šaqūra ${ }^{26}$. La amelía de Segura era el confin noreste hacia la kūra de Tudmìr con una delimitación que discurriría, aproximadamente, por los territorios de Alcaraz (al-Karaz), Riopar, Molinicos, Férez (Farīš), Socovos ( $\breve{S} a q u \bar{u} b \bar{u} s$ ), Yeste, la Graya (al-Qurayya) y Taibilla ${ }^{27}$. La cora de Jaén también estuvo sometida a las tensiones de la fitna de los últimos años de califato, situación que provocó la división y desmembración de su territorio. Los diferentes grupos étnicos existentes en su territorio acentuarían sus políticas de asentamiento y formarían unidades políticas independientes ${ }^{28}$. Uno de los territorios que se desgajó fue Šaqūra cuando era gobernada por Alboacén, un ámel que llegó a ser rey de Murcia hacia 421/103029. Más tarde, en 435/1043-44, el gobernador del enclave serrano fue Sa ī $\mathbf{d}$ b. Ahmmad b. Zanfal al-Ğumanī, un muladí también conocido como Sa '̄id b. Rafîl, que formó parte de una coalición contra los beréberes formada por al-Muqtabir b. Hūd, emir de Zaragoza. Hacia 465/1075, Šaqūra perteneció a los territorios de Denia bajo el gobierno de 'Alī b. Muğāhid Iqbāl al-Dawla y, cuando sus posesiones fueron ocupadas por Ibn Hūd, la fortaleza de Segura se independizó bajo el mandato de su hijo Sirāğ al-Dawla ${ }^{30}$. En 483/1091 la plaza es ocupada por los almorávides comandados por Batī $b$. Ismā $\overline{1}^{31}$.

Con la progresiva islamización de al-Andalus se va consolidando un proceso paulatino de urbanización que llega a su máxima expresión con el sistema de ciudades almohade. Para sostener ese desarrollo urbano probablemente sería necesario incrementar las rentas productivas agrarias. Esta circunstancia estimularía procesos de colonización interna con el fin de ampliar la explota-

25 Al-Wațwāṭ en su Manāhiğ al-fikar, trad. Fagnan, Extraits, p. 60.

26 La amelía o 'amal es un término empleado para describir un área de dependencia administrativa o distrito de características aparentemente similares a las de otras unidades territoriales como el iqlìm o distrito de economía agrícola y el ğuz' o distrito con vocación pastoril y otro régimen fiscal. Al-Zuhrī cuando se refiere al hiṣnn Furnus dice que está en el 'amal de Šaqūra. Al-Zuhrī, Kitāb al-Ǧa 'rāfiyya, parágrafo 253, p. 209. La relación de dependencia administrativa de Šaqūra de la kūra Ğayyān se recoge en la biografía de al-Šaqūrī en la que se afirma que «era de la gente de la fortaleza de Fargalīt de las dependencias de Segura de la cora de Jaén». Martínez, Al-Andalus, p. 336.

27 Vallvé, La división territorial, pp. 274-275.

28 Quesada, "El poblamiento medieval”, pp. 168-172.

29 Cruz, "El reino taifa de Segura", p. 886.

30 Vallvé, "La división territorial", p. 76.

31 Vidal-Castro, "Šaqūra", p. 23. ción de tierras. Durante el siglo XI, se produce en al-Andalus un importante crecimiento demográfico junto con una intensificación agraria, que ha sido denominada por Bolens como la 'revolución agrícola andalusí' ${ }^{\prime 32}$. Un impulso rural que posiblemente sería soporte del crecimiento urbano. Sin embargo, se da la paradoja que para realizar colonizaciones interiores es necesario contar con pobladores y una de las consecuencias que tiene el auge urbano es la emigración de la población del campo a la ciudad. Es posible que ese incremento demográfico se viera favorecido por las migraciones de grupos clánicos beréberes que se establecieron en numerosos puntos de la geografía de al-Andalus en sucesivos periodos. Estas tribus norteafricanas, con un alto grado de coherencia social, llegaron en los primeros tiempos de la conquista a requerimiento de necesidades militares o políticas, pero cuando hubo una cierta consolidación y estabilidad comenzaron otros tipos de desplazamientos y establecimientos de carácter civil ${ }^{33}$ que, al desarrollar modelos de implantación similares a los de sus lugares de origen, contribuirían de manera determinante a la «berberización» de algunas regiones de al-Andalus ${ }^{34}$.

En las comarcas periféricas a la Sierra de Segura, hay noticias de asentamientos en cotas bajas de tribus beréberes como los Ayt Barra en Tobarra (654 m s.n.m.) o los Ayt Yetture en Liétor (638 m s.n.m.) o en Letur (737 m s.n.m. $)^{35}$. Aḥmad al-Rāzì menciona una ciudad llamada $R \bar{l}-$ miyya o Raymiyy ${ }^{36}$, también conocida como madīnat Banū Rašìd. Los Banū Rašīd eran una tribu beréber del linaje de los Zanāta cuya implantación en al-Andalus fue tardía, en torno a los siglos XIII y XIV ${ }^{37}$. La localización de esta ciudad es incierta, aunque se suele situar en algún lugar del Campo de Montiel $^{38}$, zona también limítrofe

32 Bolens, "La revolution agricole", pp. 121-141.

33 Al-Rāzī en Nafḥ al-țīb dice: «...y se transmitió (la noticia) a la gente de la otra orilla del estrecho (al- 'Udwa) de la conquista de al-Andalus por Tāariq y de sus abundantes riquezas; entonces acudieron hacia él de todas partes y cruzaron el mar sobre cualquier cosa que flotara...». Fajri al-Wasif, "La inmigración de árabes", p. 212.

34 Martínez, Al-Andalus, pp. 452-458.

35 Navarro, "El tamaño de los sistemas hidráulicos", pp. 182-185.

36 Aguirre y Jiménez, Introducción, pp.144-145.

37 Martínez, Al-Andalus, p. 453.

38 Barceló indica que Raymiyya podría haber estado cercana a la actual ciudad de Almedina (Ciudad Real), Barceló, "Sistemas de irrigaciones", p. 60. Unos autores ubican esta ciudad entre Alcázar de San Juan y el río Dañador y otros en los alrededores de Tíscar en Quesada (Jaén). Aguirre y Jiménez, Introducción, p. 145. 
a las montañas segureñas. En el interior de las comarcas serranas de Segura, la toponimia, las fuentes documentales o los escasos registros arqueológicos, no muestran la presencia de población beréber. Sin embargo, la existencia de un patrón de asentamiento ligado a espacios agrícolas irrigados en el fondo del valle de los ríos Hornos y Guadalimar (722 m s.n.m.) plantea la hipótesis de un posible establecimiento de ese grupo étnico en estas tierras bajas, permeables y fácilmente comunicadas con las regiones limítrofes.

Como aconteció en otros lugares de al-Andalus, como el valle del Guadalquivir, el levante peninsular o la Serranía de Ronda ${ }^{39}$, es posible que en las comarcas de Segura también existiera durante el siglo XI y gran parte del XII, un tipo de poblamiento mixto. En las tierras altas este estaba formado por una población de cristianos andalusíes, muladíes y grupos de origen árabe o yemení, cuyos recursos productivos habrían sido la madera, el pastoreo o la agricultura, y en las tierras bajas por una incipiente población beréber centrada en procesos de producción basados en agricultura intensiva. Esos recursos económicos y productivos, necesariamente interrelacionados geográficamente entre sí, provocarían no pocas tensiones, conflictos y revueltas entre diferentes grupos étnicos establecidos en una misma comarca que, probablemente, terminarían con la dominación almohade ${ }^{40}$.

Los intensos cambios productivos, sociales $\mathrm{y}$ territoriales que se produjeron en al-Andalus durante el siglo XI se vieron reflejados y descritos en las crónicas y libros de la centuria siguiente. Tras el periodo almorávide, a mediados del siglo XII, los geógrafos al-Idrīsī y al-Zuhrī describen al-Andalus con un grado de conectividad entre hușūn, qurà y mudun que muestra la existencia de una articulada organización del territorio y una forma de entender la gestión y administración del mismo. Al-Idrīsī en su obra Kitāb Ruğğār o al-Kitāb al-Ruğğā $r \bar{l}^{41}$

39 Martínez, Al-Andalus, pp. 424-425.

40 Quesada, "El poblamiento medieval", pp. 171-175.

${ }^{41}$ El título exacto del libro es Kitāb Nuzhat al-muštāq fi ihtirā $f$ al-ăfāq (Recreo de quien desea ardientemente recorrer el mundo). Se conservan dos copias de los mapas del libro. La más antigua está datada en torno al año 699/1300 y se encuentra en la Bibliothèque Nationale de París. La otra copia, fechada en El Cairo en 860/1456, está en la Bodleian Library de Oxford. Esta última parece ser que fue la utilizada por Konrad Miller para la edición y publicación de los mapas árabes transliterados en su obra Mappae Arabicae entre los años 1926 y 1931. Piqueras y Fansa, "La Península Ibérica”, p. 474.
(548/1154) representa la ciudad de $\check{S} a q u \bar{r} r a$ dentro del Clima IV, sección 1 de sus mapas. En su otro libro, titulado Uns al-muhağ, describe esta madina conectada con otras ciudades, indicando las distancias que hay hasta Iznatoraf (Hiṣn al-Turāb), Baeza (Bayyāsa) o Calatrava (Qal at Rabāh). También expone con detalle el itinerario que hay desde Murcia (Mursiya) a ğabal Šaqūra, es decir, a la Sierra de Segura, probablemente hasta un lugar cercano a la actual población de Góntar ${ }^{42}$.

Además de esas rutas, el interior de la Sierra de Segura estaba recorrido por otras infraestructuras de comunicación y transporte terrestre, algunas heredadas de época romana ${ }^{43}$. Una de ellas era un desdoblamiento del antiguo camino de Aníbal o de los Cartagineses que dejaba el río Guadalmena y se introducía por el interior del valle del río Guadalimar. Esa vía se bifurcaba, a su vez, dentro del valle en otras dos estradas: el camino Collado de las Almendros que iba por el Tranco hacia Granada y el camino del Arrecife que, pasando por La Puerta de Segura, partía hacia Calatrava y también a Baeza y Córdoba.

Al-Zuhrī, en la descripción que hace de la comarca en el Kitāb al-Ğa 'räfiyya (ca. 548/1154), insiste en la cercanía de la frontera: «...hacia la alquería conocida como Mesones (Mī̌sūniš) (...) es la primera zona fronteriza (tagr $r)$ de los musulmanes (...) el río llamado Guadalmena (wād $\bar{l}$ Armāma) que desciende desde la zona fronteriza de Alcaraz (al-Karaz) $\rangle^{44}$. Es posible que, debido a esa cercanía y a que los valles del Guadalimar y del Guadalmena están separados por la Sierra de Alcaraz y la Serranía de Oruña, los caminos interiores de la Sierra de Segura se convirtieran

42 Al-Idrīsī indica que la distancia de Murcia a Segura es de 75 millas $(139 \mathrm{~km})$, apostillando «otros dicen que son 90 millas» (167 km). Al-Idrīsī, Uns al-muhağ, pp. 91-92. El primer lugar correspondería a un punto cercano a la población de Yeste (Albacete). La segunda indicación correspondería a un lugar cercano a Góntar (t.m. de Yeste). En cualquier caso, para llegar desde esa población a Segura todavía es necesario atravesar toda la sierra. La distancia a pie, desde Góntar hasta Segura de la Sierra, son 23 millas $(43 \mathrm{~km})$ por lo que serían necesarias como mínimo dos etapas más. La primera etapa sería, probablemente, hasta la mitad del recorrido, cerca del Castellón-Cortijo de la Morilla (1560 m s.n.m.), que es la cota más alta de la ruta. La siguiente etapa iría desde ahí a Segura de la Sierra a la que se entraba, pasando entre la torre y el cerro de Góntar, tras recorrer 45 farāsih o parasangas $(250 \mathrm{~km})$ en 11 etapas o postas.

43 Cruz, “¿Otra vía romana entre Cástulo y Cartagena?”, pp. 35-44. Zanón, "Un itinerario", pp. 41-42.

44 Al-Zuhrī, Kitāb al-Ğa 'rāfiyya, parágrafo 255, p. 209. 


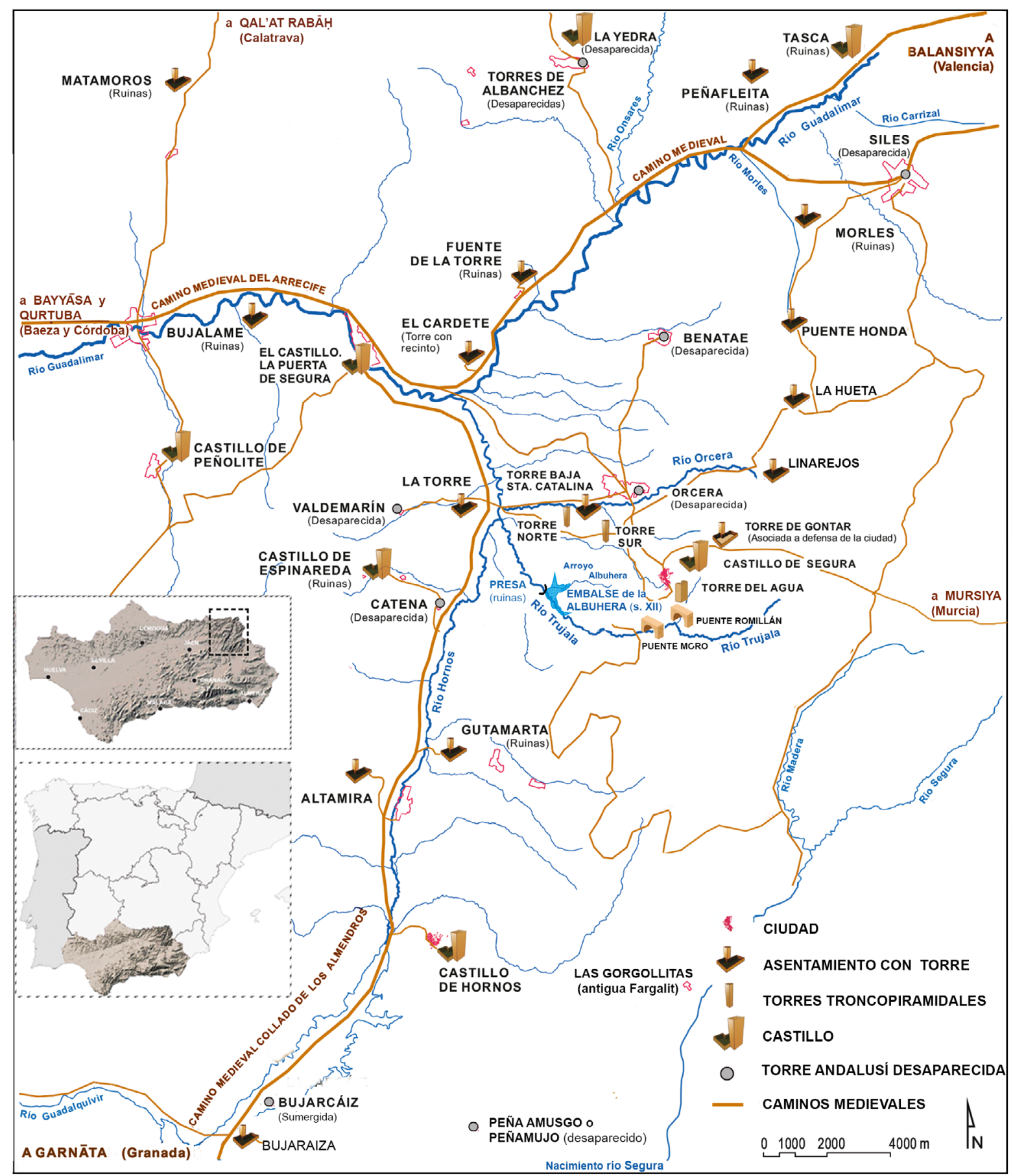

Fig. 3. Territorio del valle de los ríos Guadalimar, Hornos y Trujala con indicación de los establecimientos rurales, ciudades, castillos, vías de comunicación, cursos fluviales e infraestructuras hidráulicas. Fuente: elaboración propia.

en una alternativa a la antigua calzada romana, ya que debían de estar más protegidos que el tradicional camino hacia levante (Figura 3).

En el siglo XII, las crónicas árabes dan noticias de un andalusí llamado Abū Ishāa ibn Hamušk que se sublevó en 538/1144 contra los almorávides en hiṣn Šaqūbūš (Socovos), apoderándose en 541/1147 de Šaqūra. A partir de ese año, estas comarcas estarían controladas por él como lugarteniente de su yerno Ibn
Mardanīš, también conocido como el rey Lobo por los cristianos. Durante un cuarto de siglo ambos frenaron la expansión de los almohades hacia el levante peninsular con una alianza que duró hasta el año 564/1169 cuando Ibn Hamušk adoptó la doctrina unitaria de los norteafricanos, propiciando tres años después la conquista de Valencia por los al-muwahhidūn o unitarios.

De la importancia que hubo de tener Ishāa ibn Hamušk en la comarca segureña dan testi- 





Fig. 4. Mapa de Segura de la Sierra y Orcera con la ubicación de las tres torres conservadas en los llanos de Sta. Catalina: Torre del Aguadero, Torre Norte y Torre Sur, así como la red de caminos que pasaban junto a ellas, incluyendo el trazado del Cordel de La Mancha. Nótese el desvío del Cordel para pasar junto a las Torres Norte y Sur. También se ha señalado el embalse de la Albuhera cuyas aguas, provenientes del río Trujala, regarían las tierras donde se ubican las torres de Sta. Catalina, drenando al río Orcera junto a la Torre del Aguadero. Se señalan también Amurjo, el Puente Moro y el Puente Romillán. Fuente: elaboración propia con información cartográfica de 1878 y 1899.

monio la toponimia y sus obras. Cerca de Orcera hay un conocido paraje llamado Amurjo, citado en las Relaciones de Felipe II como

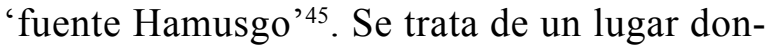
de hubo una ermita, donde el río Orcera creaba unas piscinas naturales hasta hace poco y donde todavía subsisten las ruinas de un molino harinero. También entre el actual pantano del Tranco y el nacimiento del río Segura, hay otro punto que se llama Peña Amusgo o Peñamujo, un sitio donde había un castillo que, desde la altura dominaba el río Guadalquivir $\mathrm{y}$, desde la cercanía, la salida del río Segura hacia Murcia. Además, aún quedan importantes restos de una obra hidráulica construida por Isḥāq ibn Hamušk. Se trata de una presa construida en hormigón de cal y canto destinada a cerrar un desfiladero llamado Halq al-Ayyil (Garganta del Ciervo) con el fin de derivar las aguas del río Trujala hacia las zonas cultivables de los llanos de Santa Catalina y con la que, según al-Zuhrī, «(Ibn Hamušk) transformó todo aquel campo en un mar» ${ }^{46}$. Una imagen que aún guarda la memoria del lugar a través de la toponimia que denomina esos terrenos y un pequeño arroyo que atraviesa la cuenca con el nombre de Albuhera (al-Buhayra) o 'el mar pequeño' (Figura 4).

El geógrafo al-Zuhrī describe este territorio serrano en estos conocidos y citados términos: «El monte está junto a fağğ al-Daylam del ğabal $\check{S} a q \bar{u} r a$, que es un monte grande, muy fértil, lleno de ganado, árboles y frutos, con abundancia de edificaciones y viviendas. En él hay, entre qurà, mảāqil y hușūn, 300 qurà y 33 hussūn. En lo alto de ese monte está la ciudad de $\dot{S} a q \bar{u} r a$,

45 Villegas y García, "Relación de los pueblos", p. 184.

46 Al-Zuhrī, Kitāb al-Ğa 'rāfiyya, parágrafo 255, p. 208

Esta presa ha sido recogida, descrita y citada por varios autores contemporáneos. El primero que lo hace en castellano es Joaquín Vallvé, que la menciona en 1969 en su artículo "La división territorial de la España musulmana. La cora de Jaén”, pp. 76-77. Más tarde la vuelve a mencionar, de forma algo más extensa y ajustada al texto de al-Zuhrī, en el libro La división territorial de la España musulmana, pp. 131-132. Sobre los restos de esta presa y el embalse andalusí de la Albuhera nuestro equipo continúa investigando y tenemos previsto publicar en breve los resultados de los hallazgos alcanzados hasta el momento. que es la ciudad más inexpugnable de Al-Andalus» ${ }^{47}$. En la actualidad, el territorio aproximado de lo que debió de ser la amelía andalusí tiene, sin contabilizar los despoblados históricos ${ }^{48}$, 204 núcleos de población (aldeas, pedanías, cortijadas, núcleos principales...), distribuidos en 29 municipios $^{49}$.

En la sociedad y cultura medieval musulmana, en las que la ciudad tuvo una gran significación y existió una preponderancia del medio urbano sobre el rural, cabe destacar, aún más, la anterior descripción porque va más allá de reflejar la productividad y beneficios del lugar, aspectos habituales en las crónicas árabes. El panorama descrito, tanto por al-Zuhrī como por al-Idrīsī, transmite un medio rural con una alta densidad de población, conectado a una red de caminos y con un grado importante de explotación de la tierra (madera, ganadería, agricultura), ligada siempre a las cuencas de los ríos. Un rico paisaje que demuestra la presencia, en la primera mitad del siglo XII, de una organización estructurada del territorio que prefigura el esqueleto del posterior desarrollo del sistema de ciudades que implantará el Estado almohade.

En 591/1195, el tercer califa almohade Abū Yūsuf Yảqūb al-Manșūr derrota a Alfonso VIII de Castilla en la batalla de Alarcos (Ciudad

47 Al-Zuhrī, Kitāb al-Ğa 'rāfiyya, parágrafo 254, p. 209. Como se ha indicado anteriormente, con ğabal Šaqūra el geógrafo se está refiriendo a la Sierra de Segura, no solo al monte donde se ubica la ciudad. Desconocemos qué espacio sería fağğ al-Daylam, aunque podría tratarse del valle formado por los ríos Trujala, Hornos y Trujala. El nombre podría ser una referencia a un lugar citado en el Corán como Daylam, que alude a un territorio existente al suroeste del Mar Caspio, denominado en la lengua iranía guilakí como Deylaman y habitado por una tribu ganadera que ocupa un territorio montañoso junto al río Blanco.

48 Es decir, los despoblados anteriores al siglo XX.

49 Los territorios que posiblemente integrarían la jurisdicción de la amelía de Segura serían los actuales municipios giennenses de: Segura de la Sierra, Santiago de la Espada-Pontones, Hornos, Beas de Segura, Arroyo del Ojanco, Génave, Puente Génave, La Puerta de Segura, Orcera, Benatae, Torres de Albánchez (antiguo Torre Albert), Siles, Villarrodrigo (antiguo Albaladejuelo de la Sierra). Entre los municipios albaceteños estarían: Bienservida, Villapalacios, Salobre, Alcaraz, Peñascosa, Bogarra, Molinicos, Yeste, Nerpio, Riopar, Villaverde del Guadalimar, Cotillas, Vianos, Paterna del Madera, Socovos, Férez. 
Real) a 90 millas $(167 \mathrm{~km})$ de Segura. Según relatan las crónicas, el botín obtenido en esa batalla permitió financiar un ambicioso programa de arquitectura con características constructivas y ornamentales representativas del poder almohade $^{50}$ y destinado al refuerzo de fortificaciones urbanas, así como a cambiar el antiguo sistema de marcas fronterizas omeya por una nueva organización constituida por una multitud de puntos defendidos por castillos, baluartes, torres, alquerías... ${ }^{51}$ Una iniciativa de la que la cercana amelía de Segura podría haberse beneficiado.

La memoria colectiva del esplendor de $\check{S} a$ qūra llega hasta después de la reconquista cristiana, como deja constancia al-Himyarī cuando, a comienzos del siglo XV, describe el lugar como un sitio que produce rosas de suave perfume y nardos excelentes, con presencia de tejos usados para la construcción de arcos, bellos edificios y abundante agua. El cronista transcribe además los versos que, para su tumba, dejó escritos el poeta local 'Alī b. Abī Ğa far ibn Hamušk ${ }^{52}$.

\section{Geo-localizar puntos, obtener patrones, cartografiar un paisaje}

De los paisajes que ha abarcado la revisión de las fuentes documentales de la amelía de Segura, la investigación fija su mirada en uno concreto. Un paisaje cuyo entorno natural está formado por un valle con una extensión aproximada de 8300 ha y una altitud media de 772 m s.n.m., delimitado al noroeste por la Serranía de Oruña, hacia el oeste por las Cumbres de Beas y al este-sureste por la cadena montañosa de la propia Sierra de Segura, que se anuncia en este lugar con El Yelmo (1808 m s.n.m.) y el monte Segura (1225 m s.n.m.). Esa depresión sinclinal, con forma de $\mathrm{C}$ abierta y un perfil longitudinal en $\mathrm{V}$, está conformada de una parte por el río Guadalimar, que nace en la cercana Sierra de Alcaraz y desciende desde el noreste hacia la provincia de Jaén. La otra parte está configurada por los ríos Trujala y Hornos, el segundo afluente del primero que desciende desde el sur hasta encontrarse con el río Guadalimar en las proximidades de La Puerta de Segura. El paisaje lo termina de dibujar la mano humana colocando más de cuarenta puntos entre asentamientos rurales, poblaciones, construcciones o infraestructuras con algún tipo de preexistencia medieval.

\footnotetext{
$50 \quad$ Huici, Historia politica, p. 448.

Viguera, "La organización militar", p. 32.

Al-Himyarī, Kitāb Raw ḍ al-Mi 'tār, pp. 217-218.
}

Para comprender un paisaje analíticamente - no estética, ni emocionalmente- hay que utilizar un mapa y, si no existe, hay que trazarlo, incorporando el mayor número de variables que intervienen en su conformación. Algunos de los elementos naturales que determinan un paisaje son la orografía, la orientación, la escorrentía, los vientos, la red fluvial, la calidad de las tierras, etc. Los elementos antrópicos son los asentamientos humanos, su antigüedad, extensión y densidad, los caminos, las plantaciones, los tipos de cultivos, etc ${ }^{53}$. La preferencia de un lugar para ser elegido como asentamiento, cuando no responde a criterios funcionales de planificación previa como ocurre en el caso de los hușūn que surgen por motivos defensivos, obedece a la combinación de un conjunto de variables relacionadas entre sí. Una implantación con carácter habitacional o productivo suele estar determinada o condicionada por diversos factores, dependientes e independientes, que interactúan entre sí. Estas variables se pueden definir como los distintos aspectos de la realidad que inciden, de alguna manera, en las ventajas o inconvenientes de las alternativas disponibles para solucionar el problema de la ubicación de un asentamiento humano. La cuantificación y conocimiento de cómo aparecen, influyen y se combinan estas variables facilitan la comprensión del emplazamiento de los asentamientos rurales, ya que permiten incorporar la relación o dependencia que tienen respecto al espacio físico en el que se emplazan, se pueden comparar entre sí y es posible establecer una clasificación territorial, previa o complementaria a la caracterización tipológica-funcional del yacimiento o asentamiento. La cuestión, pues, no solo es determinar qué tipo de datos hay que describir ${ }^{54}$, sino sobre todo cómo se pueden obtener y procesar los parámetros existentes en el paisaje para llegar a conclusiones sólidas.

El punto de partida obligatorio para la exploración de un paisaje históricamente antropizado como el de la Sierra de Segura ha sido la revisión de las fuentes documentales y escritas, así como el estudio de fuentes cartográficas, actuales e históricas. Esa información se completa con un exhaustivo trabajo de campo en el que se hace una prospección intensiva del territorio y el registro de las preexistencias conservadas en

\footnotetext{
53 Caniggia, Strutture dello spazio antropico.

54 Malpica, "El paisaje”, pp. 146-153.
} 
él. La carencia de campañas de excavaciones arqueológicas intensivas y la escasa información suministrada por las dos prospecciones extensivas realizadas hasta el momento en el entorno de Orcera (Cerro de la Coja, Mesa del Cementerio, arroyo de Claudio, llanos de Sta. Catalina) no han sido determinantes para datar los asentamientos y restos existentes en la zona ${ }^{55}$.

Sin embargo, los vestigios y estructuras del valle de los ríos Trujala, Hornos y Guadalimar son auténticos fósiles históricos incrustados en el paisaje y una importante fuente de información primaria. Por ello, se hace un extenso inventario para datarlos cronológicamente y analizarlos desde el punto de vista arquitectónico, estratigráfico y constructivo. Ese trabajo conlleva el levantamiento fotogramétrico de todas las fábricas a escala 1:50, así como el estudio pormenorizado de técnicas y materiales de los restos. Para establecer su cronología se procede al cruce de los resultados obtenidos con la datación por C14, las estratigrafías y la caracterización de la técnica constructiva.

El estudio estratigráfico ha revelado la presencia de revocos simulando falsos sillares en las fábricas de tapial de la torre de Góntar (Segura de la Sierra) y en los muros exteriores del recinto de El Cardete (Benatae) ${ }^{56}$. Se trata de un tipo de decoración parietal existente en arquitecturas defensivas musulmanas, frecuente en construcciones almohades, aunque también presente en otros periodos y épocas ${ }^{57}$. La data-

55 En 2004, se hizo una prospección extensiva en el entorno de las torres de Sta. Catalina con motivo del trazado de una línea de alta tensión sin resultados relevantes. Bellón, Rueda y Sánchez, "Prospección arqueológica", pp. 572-581. Anteriormente, en 1987 se realizó una prospección arqueológica en la cueva Piedra del Aguila, ubicada en el Cerro del Pavo cerca de Valdemarín (Orcera), documentando la existencia en su interior de una gran cantidad de material cerámico caracterizado por grandes vasijas contenedoras destinadas al almacenaje. Crespo y Pérez, "Prospecciones arqueológicas", pp. 329-333. Entre 2014 y 2016 se ejecutó una excavación arqueológica intensiva en esta cueva de cuyos resultados se extrae como conclusión que la gruta habría sido una «cueva santuario extraurbano» en época ibera, parte de la expansión del oppidum de Bujalamé. Rueda y Bellón, "Culto y rito", p. 53. En los resultados publicados hasta el momento no hay mención a posibles ocupaciones posteriores al siglo III a.e.c., ni registros o vestigios de culturas posteriores. Una circunstancia que sería ciertamente singular, al menos en una comarca tan antropizada y habitada como esta.

56 Quesada-García y Romero-Vergara, "El sistema de torres", p. 27.

57 El revoco de las fábricas de tapia con dibujos de despiece de falsos sillares es un acabado atribuido a los almohades. Azuar et al., "El falso despiece", pp. 245-278. Aunque es una ción de muestras procedentes del calicostrado y maderas de las fábricas de tapia aporta datos más concretos para establecer una cronología precisa. Los análisis realizados sobre muestras de Peñolite, El Cardete, El Castillo y las Torres Norte y Sur de Santa Catalina indican una horquilla de tiempo comprendida entre los años 408/1018 y 559/1164. Si se considera además la caracterización de la tapia, ejecutada con una técnica muy similar, en construcción y morfología, a otras fábricas de diferentes lugares de al-Andalus, tanto rurales como urbanas, identificadas como almohades, se podrían atribuir las construcciones medievales que se conservan en este valle a los bereberes mașmūdas del Atlas, que conquistaron Segura en 564/1169 y Valencia en $567 / 1172^{58}$. Las construcciones serranas giennenses habrían sido precedentes a las que construyeron los almohades durante su implantación en el levante peninsular ${ }^{59}$.

Tras verificar la cronología de los restos existentes en los asentamientos, la siguiente fase del trabajo es la obtención de datos que permitan obtener pautas o patrones existentes en las diferentes implantaciones existentes en el valle de los ríos Trujala, Hornos y Guadalimar. Para ello, se hace un levantamiento topográfico tridimensional del terreno en torno a cada una de las preexistencias, con el objetivo de interpretar con precisión su contexto, detectar posibles permanencias, trazas ocultas o pérdidas por alteraciones antrópicas y/o naturales (Figura 5). Estas bases topográficas permiten acercarse con exactitud a cada emplazamiento y entender las relaciones con accidentes geográficos, infraestructuras, estructuras productivas, caminos o redes hidráulicas. Posteriormente se elabora un Modelo Digital de Elevaciones del territorio objeto de estudio; en él se introduce la posición de cada uno de los asentamientos

decoración que también se ha encontrado en algunas fábricas nazaríes como la Puerta Elvira en Granada. Almagro, Orihuela y Vílchez, "La puerta de Elvira”, p. 529.

58 Los argumentos que justifican la atribución a los almohades de los restos conservados en el valle se han aportado en trabajos anteriores. Quesada-García y Romero-Vergara, "El sistema de torres", pp. 28-29.

59 Cerca de la capital levantina se encuentra la torre de Bofilla en Bétera (Valencia) que es uno de los ejemplos mejor conservados y documentados de torre rural aislada construida en tapia en la Península Ibérica. Es una estructura que tiene una morfología, técnica y dimensiones muy similares a las torres serranas giennenses. La construcción de la torre levantina ha sido datada hacia 616/1220, siendo atribuida a los almohades, que la habrían construido pocos años antes de la reconquista cristiana de Valencia en 635/1238. López Elum, La alquería islámica. 
usándola como punto de referencia para obtener los diferentes datos geo-morfológicos de cada uno de ellos (Figura 6). Tras la carga y procesamiento de las diferentes capas de datos se obtienen los patrones de comportamiento estadísticos que siguen cada uno de los emplazamientos. A partir de aquí, y por medio de un modelo de Evaluación Multicriterio (EMC) también en entorno SIG, se obtienen unos mapas de distribución que indican la aptitud de cada lugar para albergar un asentamiento determinado (Figura 7). Esta información se cruza con la obtenida en otros estudios (documentales, topográficos, constructivos, estratigráficos, cronológicos, etc.), logrando unos resultados que permiten describir, cuantificar e interpretar algunos de los elementos del paisaje que concurren en cada uno de los emplazamientos y que se relacionan a continuación.

\section{Altitud relativa del emplazamiento ${ }^{60}$}

Esta variable es un elemento determinante para el control y gestión de un territorio. Los hussūn se sitúan, generalmente, en las cimas de colinas o montañas. Pero hay otros asentamientos que aparecen en pequeños altozanos o en la parte media-baja de laderas de cerros, colinas o montañas, siempre por encima de terrenos inundables ${ }^{61}$. En el valle segureño se han localizado algunos establecimientos por encima del $85 \%$ de altitud relativa (Figura 8). Sin embargo, la mayoría se sitúan en laderas o mesetas de montañas, con una altitud relativa que va desde el $18 \%$ al $30 \%$ de la altura total del collado donde se asientan. Esta situación, vulnerable desde el punto de vista defensivo-militar, permite, no obstante, agrupar y proteger la producción, recursos y patrimonios campesinos en caso de arriadas $u$ otros factores ambientales imprevisibles, además de liberar espacio para el cultivo y el regadío. También consiente que el emplazamiento esté protegido del viento, próximo a ríos, vías de comunicación y, sobre todo, cercano a las tierras de labranza dominadas visualmente desde la posición.

\footnotetext{
$60 \quad$ Para obtener conclusiones comparables acerca del posicionamiento de los asentamientos, la variable a analizar es la altitud relativa, expresada en porcentaje en relación a la montaña, cerro o llanura donde esté enclavado el asentamiento; no es la altitud absoluta respecto al nivel del mar.

${ }_{61}$ Ibn Luyūn indica en el Kitāb al-Filāha que para el emplazamiento de una casa de labor se debe elegir un altozano que facilite su guarda y vigilancia. Eguaras, Ibn Luyūn, pp. 272-274.
}

\section{Pendiente del terreno del emplazamiento}

La topografía de un terreno es un rasgo fundamental para entender las características del poblamiento, ya que la presencia o ausencia de accidentes geográficos condiciona su forma y desarrollo. La evolución de un establecimiento varía en función de la pendiente del terreno en el que se asienta. Por encima de determinados porcentajes, las construcciones y entornos comunitarios, además de encarecerse, comienzan a ser menos confortables para ser habitados o trabajados. Es incuestionable que los sitios pensados desde un punto de vista exclusivamente defensivo aprovechan escarpes con pendientes fuertes $\mathrm{o}$ inaccesibles $\mathrm{y}$, en cambio, lugares destinados a usos habitacionales o productivos buscan lugares más accesibles y cómodos. En las partes altas de la Sierra en las laderas de las montañas, donde no hay superficies planas, se construyen terrazas para los establecimientos. En el territorio analizado los asentamientos más escarpados van desde los $24^{\circ}$ a los $40^{\circ}$ de inclinación. Las estructuras del fondo del valle se asientan en terrenos con una pendiente más suave, que va desde $\operatorname{los} 2^{\circ}$ a $\operatorname{los} 18^{\circ}$, inclinación que permite una construcción asequible y económica de las edificaciones, además de una mayor habitabilidad (Figura 9).

\section{Superficie de terreno vinculada al poblamiento}

En los asentamientos de las tierras altas se construye un sistema de bancales (mảğ̌ll) destinados al cultivo, que son irrigados por la red fluvial o acuíferos cercanos. En la zona más llana y menos abrupta del valle se ha comprobado que los emplazamientos están vinculados a un área de terreno de extensión limitada. Una parte de esta superficie serían espacios de tierra comunal (harim), tierras muertas (mawāt) o pastizales por encima del espacio de irrigación. Otra parte de las tierras estarían destinadas a regadío (mamlüka), generalmente son terrenos conformados por las sedimentaciones de río que reciben el nombre árabe de ğazìra, uno de los espacios agrícolas más citados en las fuentes históricas ${ }^{62}$. Para la medición del área total de terreno vinculado a un asentamiento se han considerado, entre otras variables, los límites naturales además del recorrido que realiza una persona a pie durante una hora en terreno llano, es decir, una distancia equivalente a una pa-

${ }^{62}$ Retamero, "Irrigated agriculture”, pp. 135-147. 

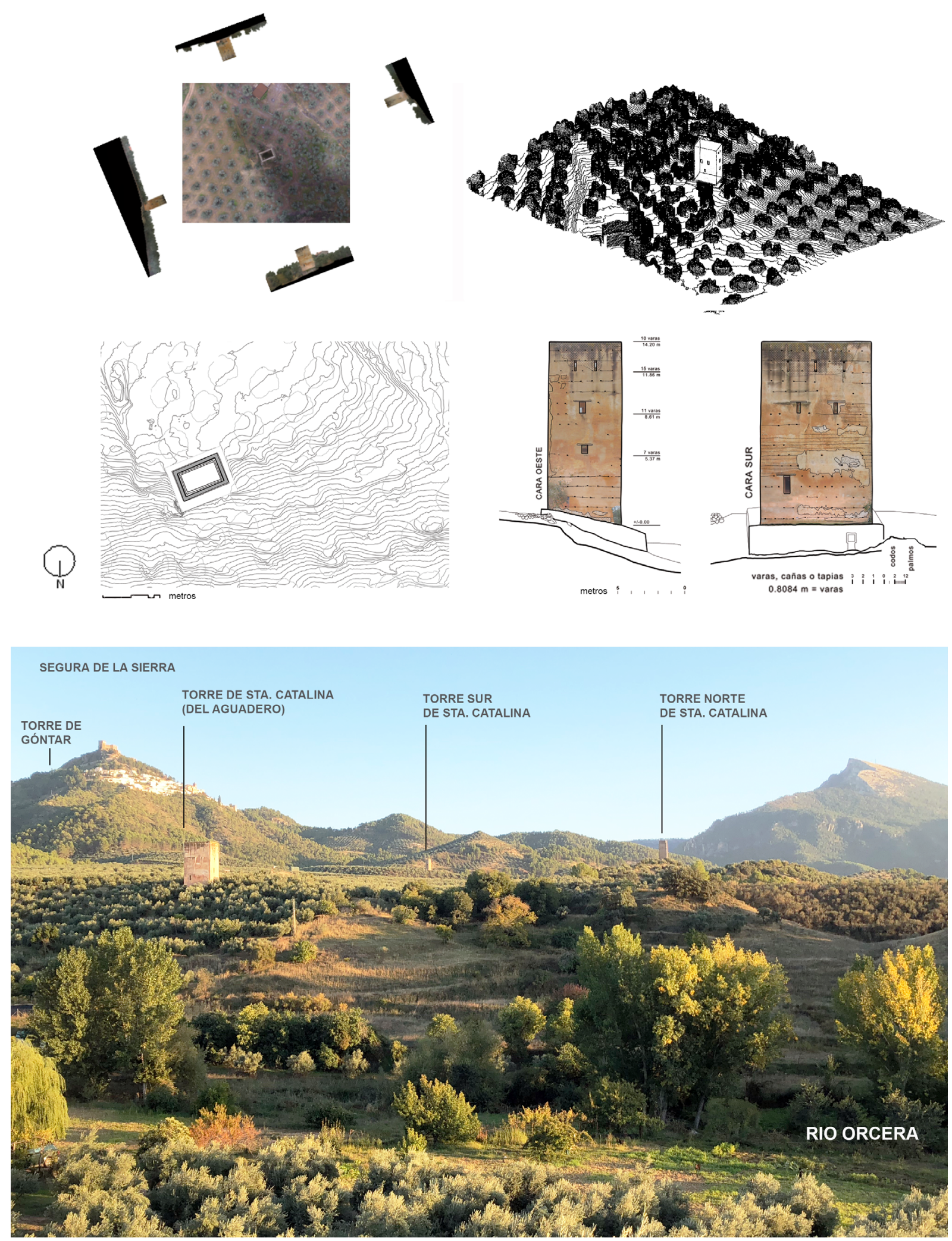

Fig. 5. Levantamiento topográfico y fotogramétrico de la Torre del Aguadero (Orcera). En el proceso de restitución se ha eliminado el olivar para revelar e interpretar con precisión las modificaciones del terreno y detectar posibles permanencias, trazados ocultos o pérdidas por alteraciones antrópicas y/o naturales. Abajo: Paisaje de huertas y cultivos visto desde el Cerro de la Coja (Orcera) hacia Segura de la Sierra con las tres torres de Sta. Catalina: la primera de ellas es la Torre del Aguadero que se asoma al cauce del río Orcera. Al fondo, puede verse el macizo de El Yelmo. Fuente: elaboración propia. 


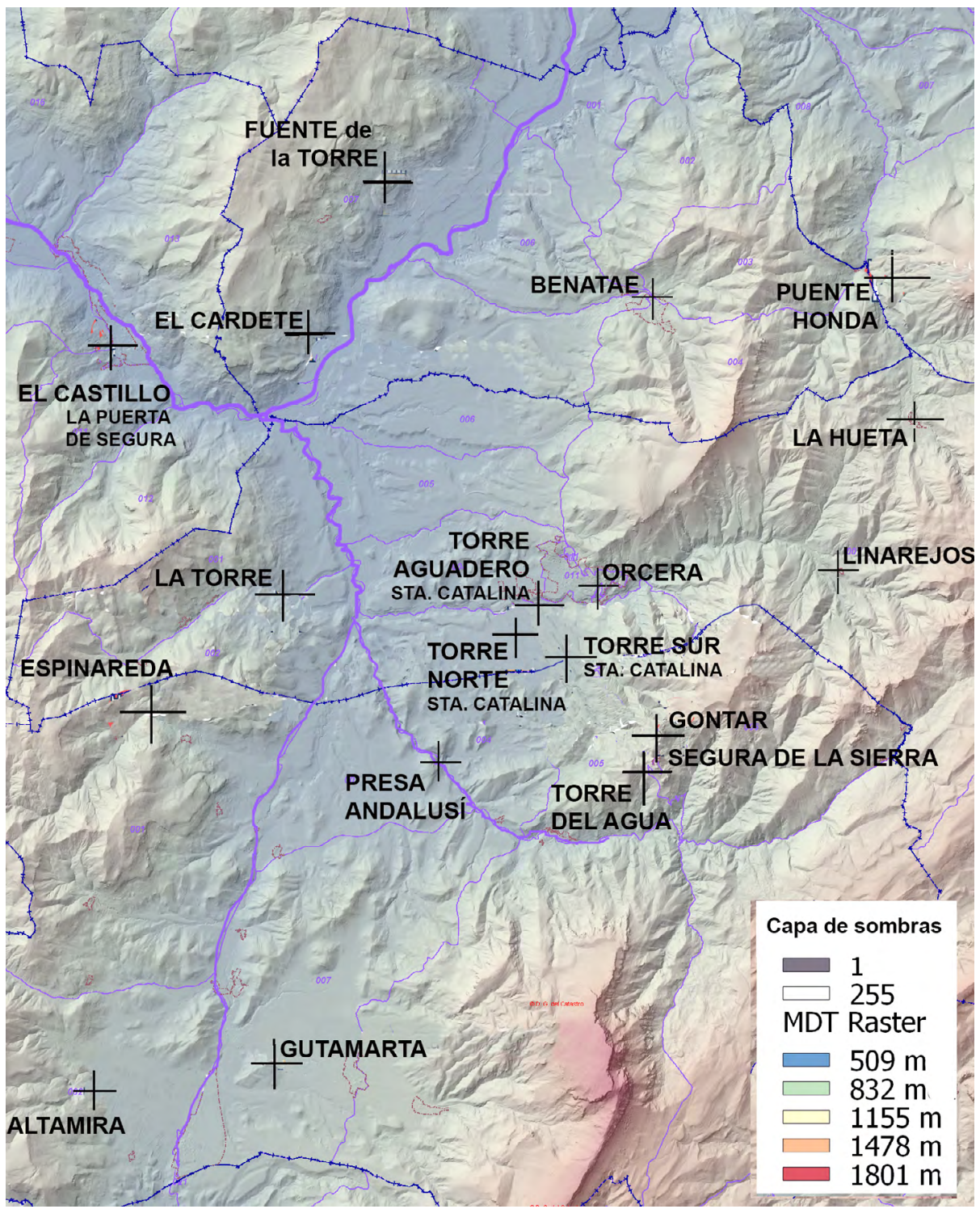

Fig. 6. Modelo Digital de Elevaciones (MDE) del territorio combinado con capa de sombras y geo-localización de todas las estructuras andalusíes estudiadas. Fuente: elaboración propia.

rasanga $(\text { farsah })^{63}$. En el fondo del valle se ha verificado que los espacios irrigados tienen una pendiente inferior a $20^{\circ}$, baja escorrentía y son fácilmente drenables e irrigables, por lo que son muy adecuados para ser trabajados y labrados sin disponer de bancales. La superficie de tierra cultivable, que podría ser denominada como haza ( $f a h s)$, está dominada visualmente desde la elevación del asentamiento y suele estar delimitada por elementos muy visibles como son colinas, barrancos, montañas, arboledas o caminos

63 La parasanga o farsah era una medida itineraria equivalente a una legua castellana que, en el sistema métrico, serían $5572,71 \mathrm{~m}$ y equivaldría a tres millas raššăšies. El codo raššāšs fue una unidad de medida establecida por 'Umar b. al-Farağ al-Raššǎšs, que grabó el patrón en una columna de la Mezquita de Córdoba. Vallvé, "La división territorial”, pp. 345-347. cercanos. La extensión de terreno cultivable o haza está comprendida entre 182 y 415 ha de tierra o 1638 y 3735 tahúllas (tahwila) ${ }^{64}$. Este dato avala la apreciación de Guichard cuando indica que el término qarya, utilizado por Ibn al-Abbār, designaba suelos con terrenos que se extendían cientos de hectáreas ${ }^{65}$; este dato contrasta con el aportado por Glick cuando indica que la extensión del territorio de las alquerías estaría entre 72 y 90 ha $^{66}$ (Figura 10).

64 Una tahúlla es una medida de superficie equivalente aproximadamente a $1118,23 \mathrm{~m}^{2}$, usada en el levante peninsular y que utiliza una cuerda mayor que la del marjal (marğa ), medida de superficie agraria equivalente a 40 codos raššasš i de lado, comprendida entre los $436 \mathrm{~m}^{2}$ y los $528 \mathrm{~m}^{2}$ según las zonas.

65 Guichard, "Le problème", p. 167.

66 Glick, Paisajes de conquista. 

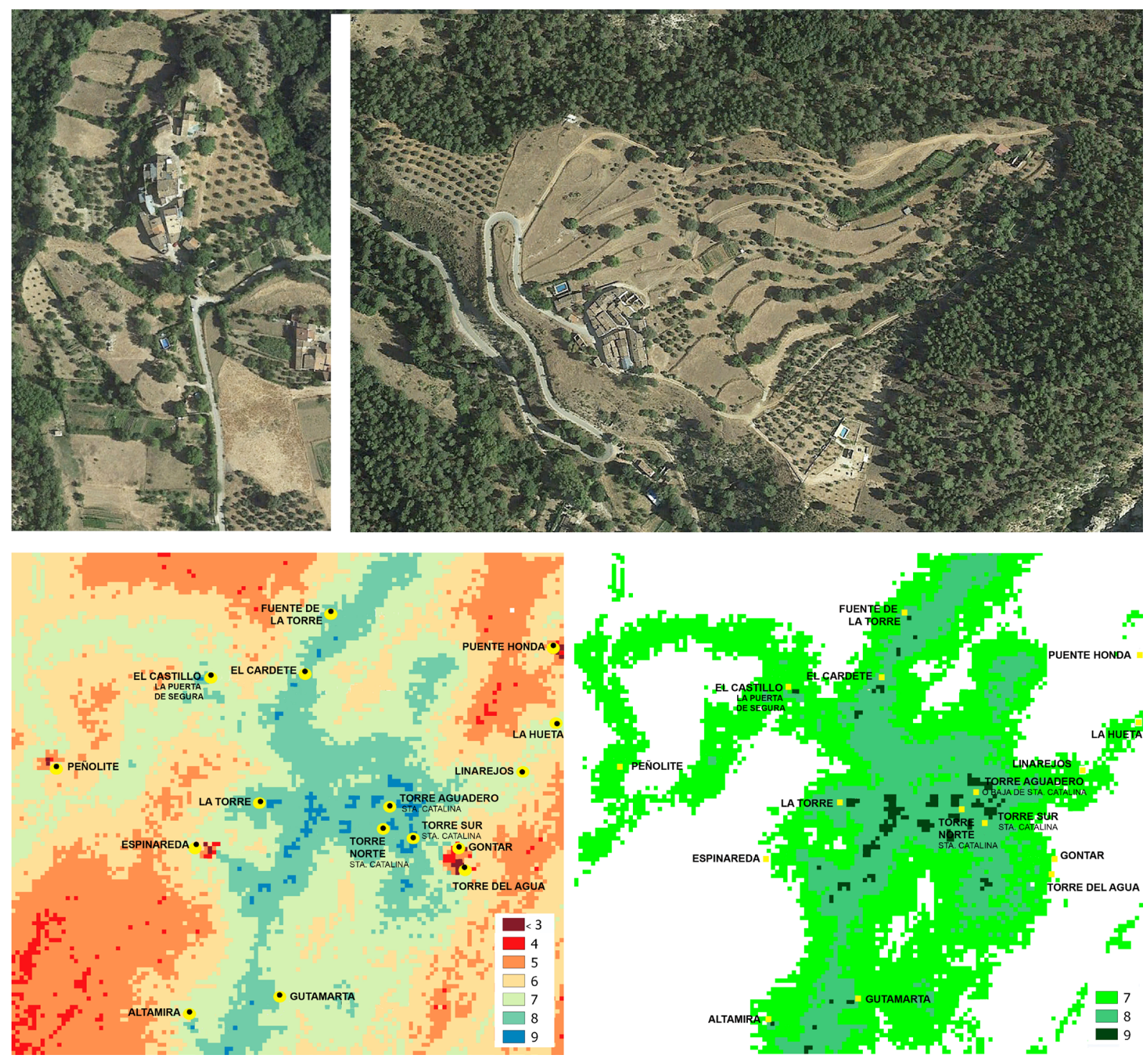

Fig. 7. Arriba izquierda: ortofotografía de La Hueta (Orcera). Arriba derecha: ortofotografía de Linarejos (Orcera) y su espacio de cultivo en bancales. Fuente: Google Earth. Abajo izquierda: mapa de distribución resultado del geo-proceso de superposición ponderada; el valor mayor corresponde a lugares aptos para alojar poblamientos habitacionales y asentamientos productivos; el valor menor corresponde a lugares inaccesibles, enriscados o con poca superficie para alojar población. Abajo derecha: resultado del geo-proceso de evaluación condicional para determinar áreas susceptibles de alojar asentamientos rurales productivos o habitacionales. Fuente: elaboración propia.

\section{Distancia a caminos y entre poblados}

El proceso de antropización del fondo del valle se intensifica cuando se colonizan sus tierras bajas. La forma más efectiva y cómoda de desplazarse por un terreno natural es siguiendo los trayectos que marcan las líneas de los cauces fluviales en las zonas bajas de los valles. En Segura, se ha observado que los caminos principales nunca atraviesan los asentamientos, se encuentran cercanos a una distancia que varía entre 252 y 322 m, equivalentes a 400 y 515 pa- sos humanos (hața ${ }^{67}$. El trayecto máximo a un camino desde un punto habitado es de $1330 \mathrm{~m}$. A partir de la matriz de datos obtenida en la zona se ha determinado que la mediana de distancia entre los núcleos rurales segureños es de 10,33 km (equivalentes a 5 millas raššăši) y que su promedio es de 11,71 km (equivalentes a algo más de 6

67 Según Ibn Ğubayr, el paso o hața contenía tres palmos mayores y era equivalente a $0,627 \mathrm{~m}$. Sin embargo, el paso citado por Ibn al-Ğayyāb era el paso de camello que equivaldría a 1,85 m o 4 codos. Una milla raššăšsi eran 1000 pasos de camello o también 4000 hatwa; equivaldría aprox. a 1857,57 m. 

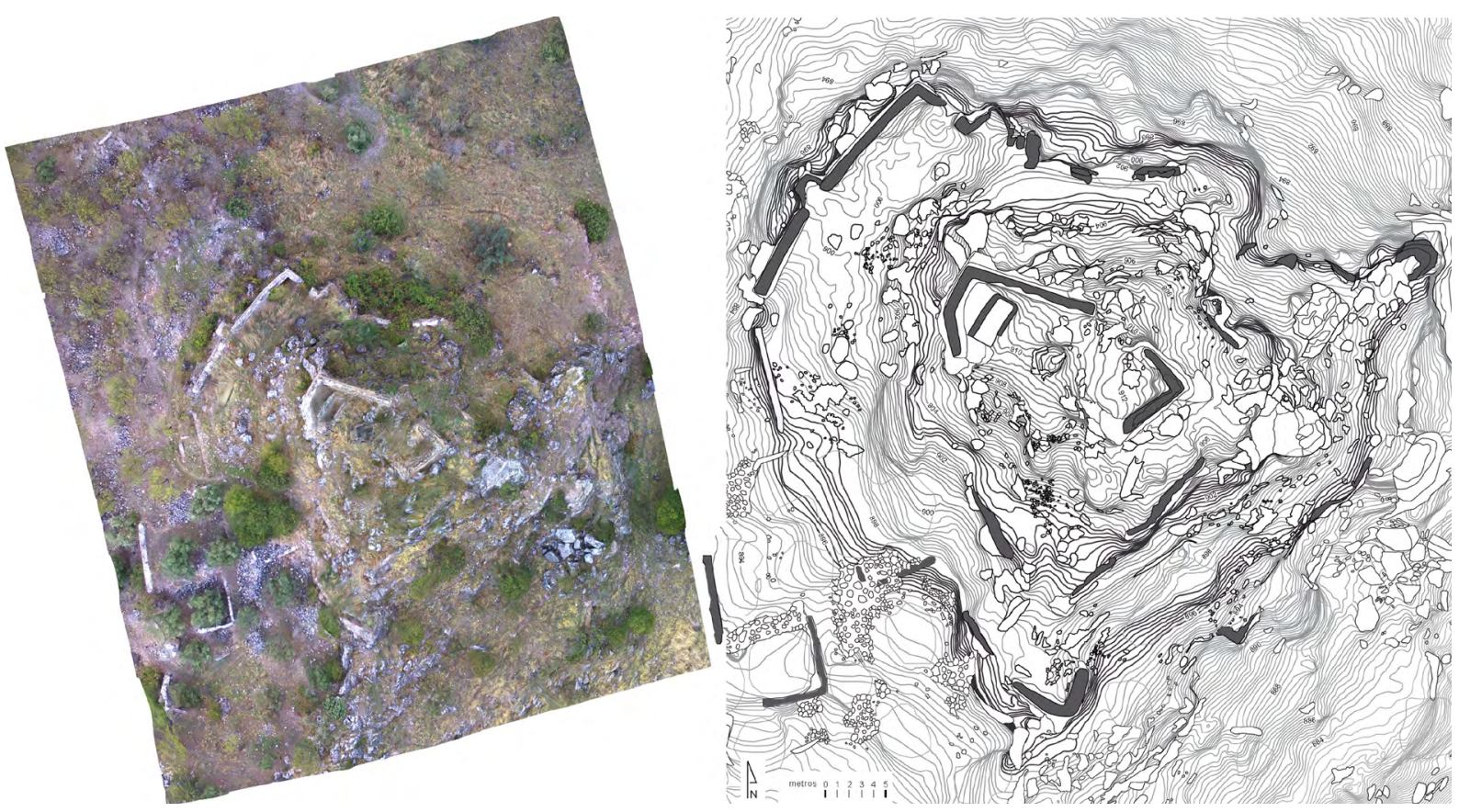

Fig. 8. Levantamiento topográfico del hișn de la Espinareda (Segura de la Sierra), un enclave de infraestructura defensiva ubicado en la entrada de una cañada de las Cumbres de Beas frente a Segura de la Sierra. Fuente: elaboración propia.

millas raššăší o 2 farāsih o parasangas), es decir, dos horas caminando por terreno llano.

\section{Distancia a redes fluviales}

La proximidad a los diferentes tipos de redes hidrológicas es otra variable a tener en cuenta. Como ocurre con los caminos, los asentamientos rurales segureños se colocan cerca de ríos y arroyos, pero no sobre sus mismas riberas. Su ubicación está a una distancia y altura suficientes como para evitar inundaciones. La separación con respecto a los cauces fluviales está en un promedio de 510 $\mathrm{m}$, distancia algo mayor que la que hay a los caminos. La posición de los establecimientos, en relación a la cercanía con la red hídrica que discurre en superficie, arroja luz a la hora de considerar que las implantaciones en cotas bajas pudieran tener funciones productivas o agropecuarias, ya que un emplazamiento estrictamente defensivo o militar se abastece de pozos, aljibes o cisternas y no tendría necesidad de disponer de los recursos de movilidad o irrigación que aporta la cercanía de un río.

\section{Ubicación en relación a acuíferos y aguas subterráneas}

La presencia de agua es determinante en la localización de cualquier asentamiento humano. Los acuíferos son zonas del subsuelo con rocas o sedimentos que contienen suficiente agua subterránea para crear un pozo o una fuente de extracción. El abastecimiento de agua potable para la población está ligado a la extracción de aguas subterráneas a través de pozos. H. Kirchner ha mostrado que la distribución de los asentamientos andalusíes en las islas Baleares se debe a la presencia de acuíferos y que estos fueron los que permitieron espacios agrarios irrigados a los que se vincularon poblamientos campesinos ${ }^{68}$. En el territorio serrano analizado en este trabajo la separación de los diferentes asentamientos con respecto a los acuíferos no es tan distante como con los ríos. En este caso varía entre los $142 \mathrm{~m}$ de Peñolite a los $739 \mathrm{~m}$ de Fuente de la Torre. Es decir, todos los enclaves habitacionales, productivos o defensivos están relativamente cerca de aguas subterráneas (Figura 11).

\section{Superficie y extensión del poblamiento}

La extensión superficial de las construcciones o restos existentes en los poblamientos prospectados, así como el número de casas y/o estructuras encontradas son importantes como variables. Estos datos permiten establecer una comparación con las edificaciones identificadas en los diferentes lugares y cuantificar su repercusión en el entorno. En el territorio segureño hay una varie-

68 Kirchner, "Redes de asentamientos", pp. 79-94. 

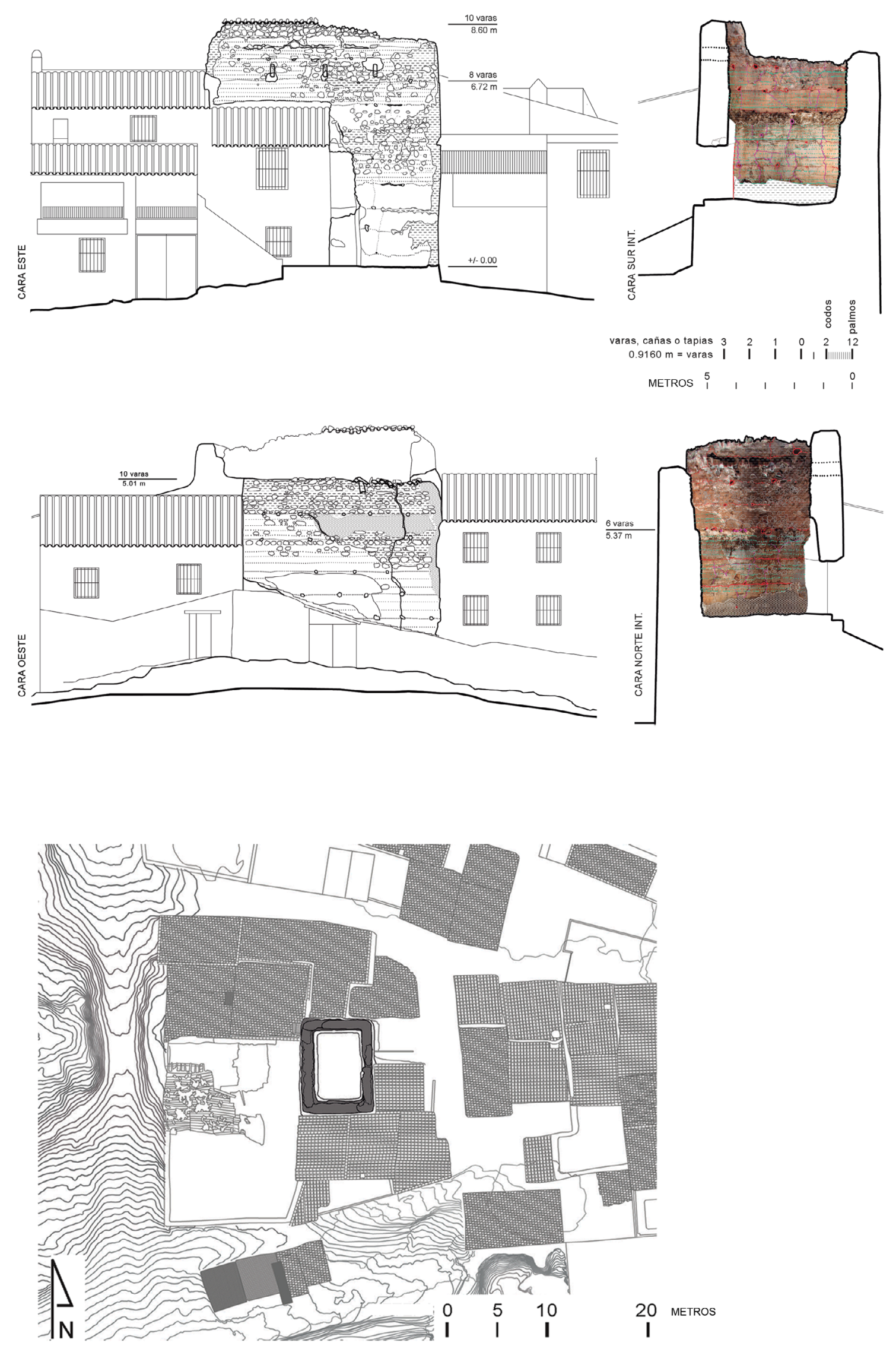

Fig. 9. Altamira (Segura de la Sierra). Se trata de un poblamiento rural habitacional, todavía habitado, que se ubica en una meseta a una altitud relativa del $20 \%$ del collado con una pendiente del terreno del $18 \%$. Altamira es el punto que une visualmente las ciudades de Hornos y Segura de la Sierra. Fuente: elaboración propia. 

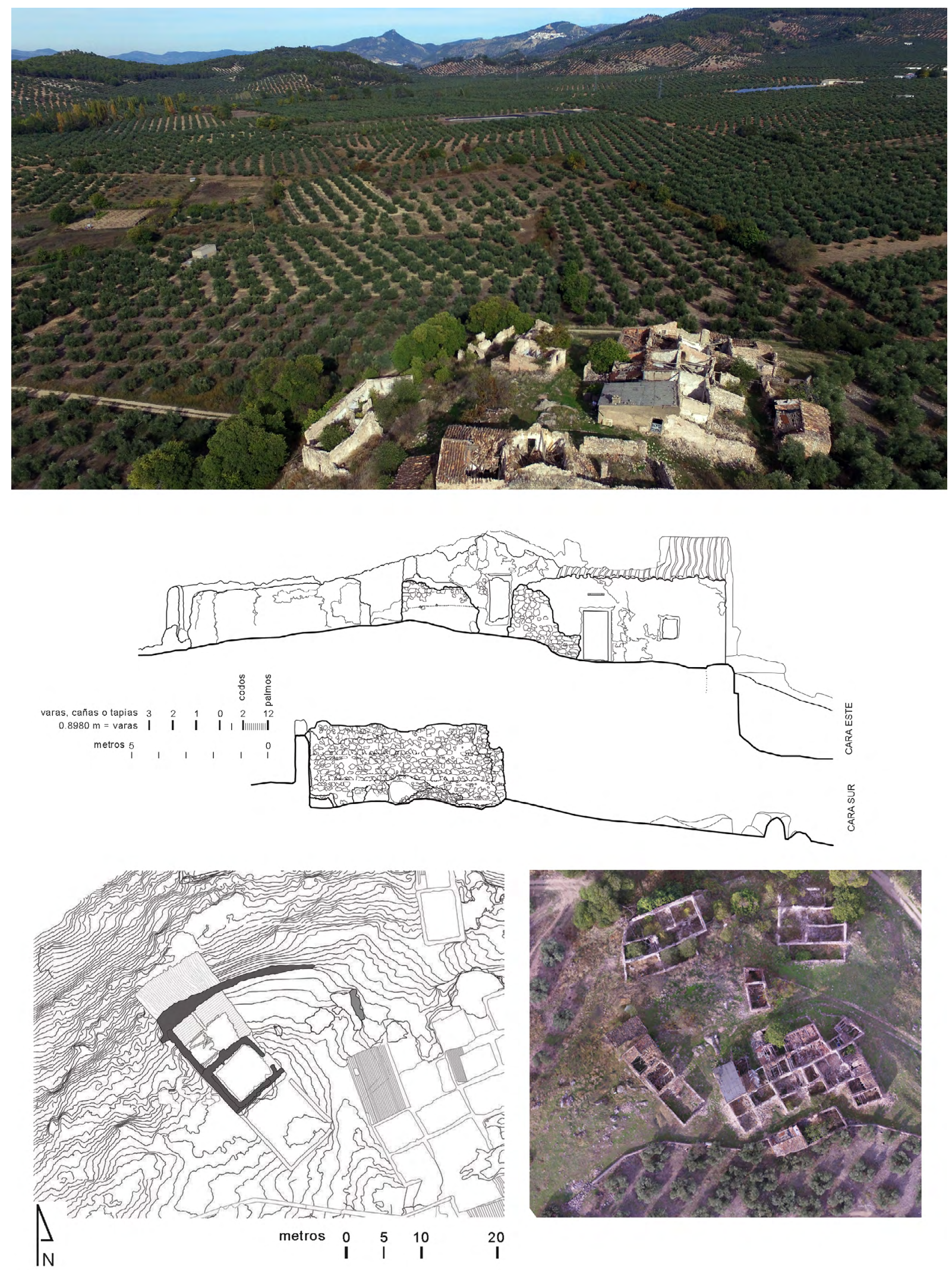

Fig. 10. Gutamarta, también llamado Los Castillejos (Segura de la Sierra). Se trata de un poblamiento rural habitado hasta fechas recientes y en ruinas en la actualidad. A pesar de ello, todavía se reconocen restos de muros y tapiales, que se han registrado y levantado. En la imagen superior se distingue el área de tierra cultivable vinculada al asentamiento con una superficie de 340 hectáreas. Al fondo a la izquierda y en bajo, se localiza Orcera. A la derecha y en alto, se hallan la ciudad y la fortaleza de Segura de la Sierra. Fuente: elaboración propia. 

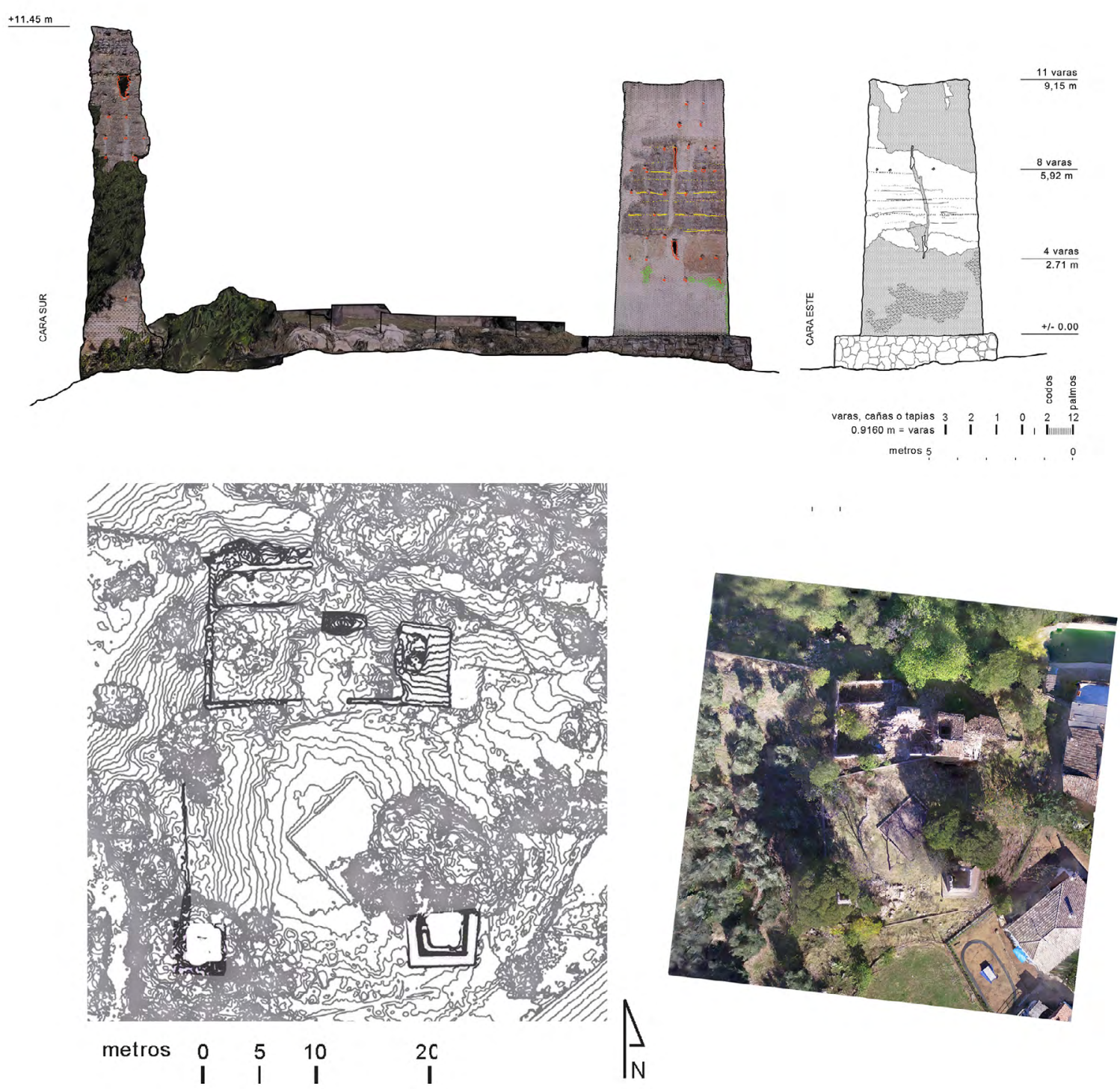

Fig. 11. Peñolite (Puente Génave) posiblemente era una alquería o un poblado fortificado con un hișn que tenía cuatro torres de las que aún se reconocen dos de ellas y los cimientos de una tercera. Fuente: elaboración propia.

dad importante de poblamientos en diferentes estados de conservación, desde aquellos que todavía están habitados a los que están en ruina. Su extensión varía entre los $7.889 \mathrm{~m}^{2}$ de Gutamarta (Segura de la Sierra) a los $4.363 \mathrm{~m}^{2}$ de Linarejos (Orcera) (Figura 12).

\section{Intervisibilidad entre poblamientos y asentamientos}

Los resultados obtenidos indican que el área visible desde la elevación de cada uno de los asentamientos es superior al $83 \%$ del territorio circundante. La presencia de torres en todos ellos sube el punto de vista y elimina los ángulos visuales ciegos que provocan las colinas o edificaciones vecinas, permitiendo un control del 95\% del territorio, así como la comunicación entre núcleos distantes entre sí. La ubicación de estas torres y su interacción con la orografía del lugar y la fortaleza de Segura parecen indicar que estas estructuras en altura debieron de estar destinadas a otros usos complementarios al de vigilancia o defensa. Posiblemente servirían también como granero, silo o para control de cultivos, regadíos, caminos e incluso para recaudación de impuestos, además de ser parte de un eficaz sistema de comunicación visual que, al alzarse sobre los tejados de las casas, permitía la conectividad visual inmediata entre lugares y poblamientos vecinos (Figura 13).

\section{Caracterización territorial del poblamiento rural de un valle de ğabal Šaqūra}

Con los resultados obtenidos se puede establecer una caracterización de índole territorial en este valle de la Sierra de Segura, agrupando cada 

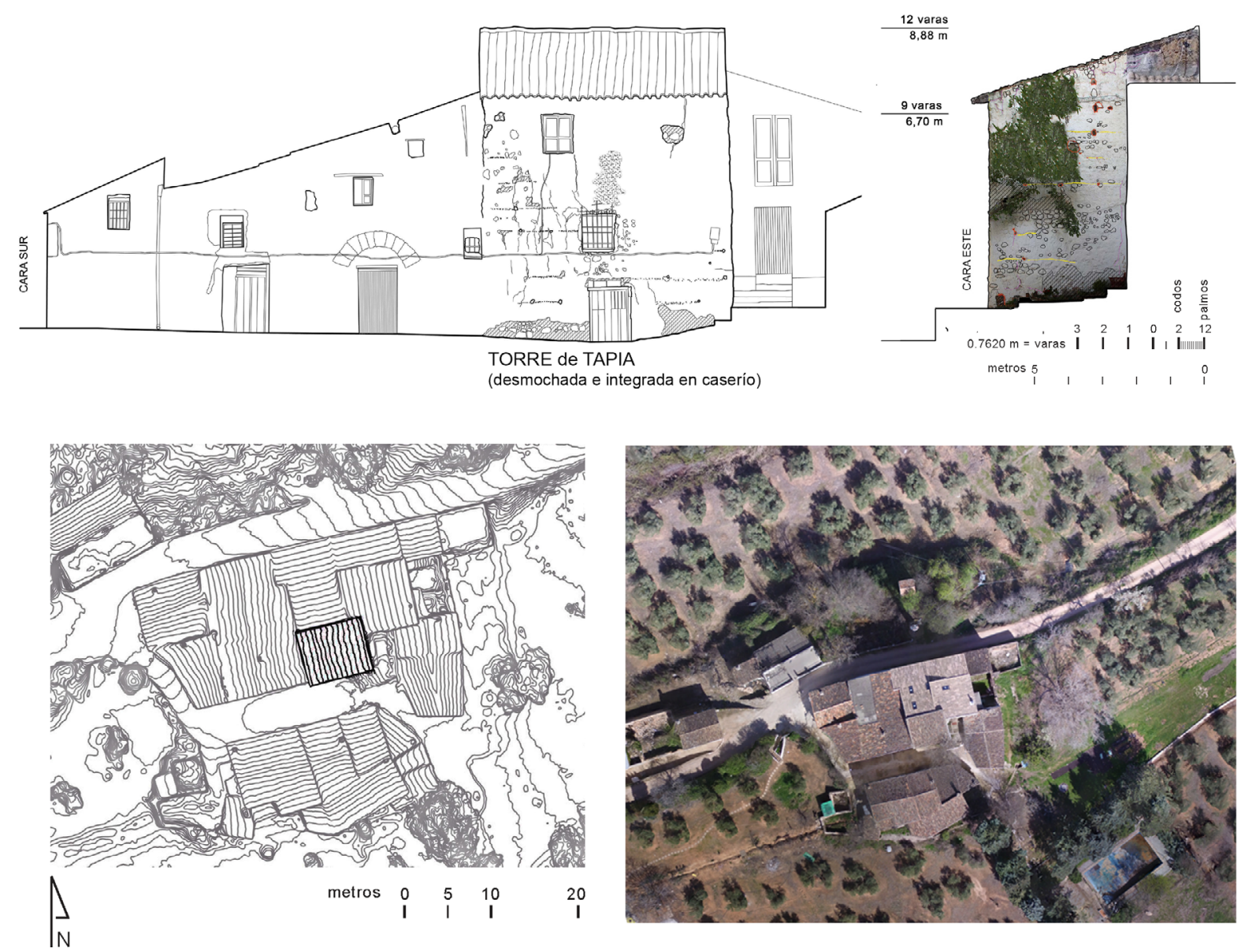

Fig. 12. La Torre, asentamiento cercano a la pedanía de Valdemarín (Orcera) y a la cueva de Piedra del Águila. La ocupación, torre y lienzos del recinto se encuentran integrados en el caserío, pero son muy visibles, lo que ha permitido su levantamiento y caracterización. La extensión superficial de este asentamiento es aproximadamente de $5.019 \mathrm{~m} 2$. Fuente: elaboración propia.

uno de los asentamientos según su grado de correspondencia con las variables del paisaje arriba descritas. Esta clasificación, que surge del análisis espacial de los establecimientos en un territorio concreto, no pretende ser universal; tampoco presupone la asignación implícita de una función o etiqueta a los establecimientos rurales. Dentro de cada uno de los grupos puede haber una o varias estructuras arquitectónicas con diferentes usos, formas y tipos. La clasificación tipológica final de los asentamientos vendrá tras las correspondientes excavaciones arqueológicas que, acompañadas de los necesarios estudios multidisplinares, podrán determinar con precisión la principal función de cada uno de los asentamientos. Sin embargo, previamente a que se realicen esos estudios, la categorización territorial planteada aquí consiente ordenar y jerarquizar los diferentes asentamientos rurales, trazando el mapa interpretativo del paisaje propuesto al principio de la investigación (Figura 14), además de clasificar los establecimientos del valle de la Sierra de Segura en los siguientes tipos de hábitats.

\section{a. Poblamientos rurales habitacionales}

Serían los emplazamientos en espacios no urbanos que servirían de alojamiento a comunidades organizadas de campesinos, con una zona de influencia cercana formada por terrenos vinculados a estos núcleos habitacionales. Pertenecerían a esta categoría las alquerías (qurà), aldeas (al-day 'a) y los poblados fortificados. En el fondo del valle, la superficie media total de terreno relacionada con cada poblamiento es de 1163,66 ha. El promedio del área de tierras cultivables irrigadas por establecimiento es de 380 ha. La altitud media relativa del asentamiento está por debajo del $30 \%$ de la altura de la montaña o collado donde se implantan y su pendiente es de $17^{\circ}$. La distancia media al cauce fluvial primario más cercano es de $497 \mathrm{~m}$ y están separados de los acuíferos $370 \mathrm{~m}$. Todos estos establecimientos tenían o tienen torres. A esta clase de hábitat pertenecerían los núcleos de La Torre (Orcera), Altamira y Gutamarta (Segura de la Sierra), Bujaraiza (Hornos), El Cardete 

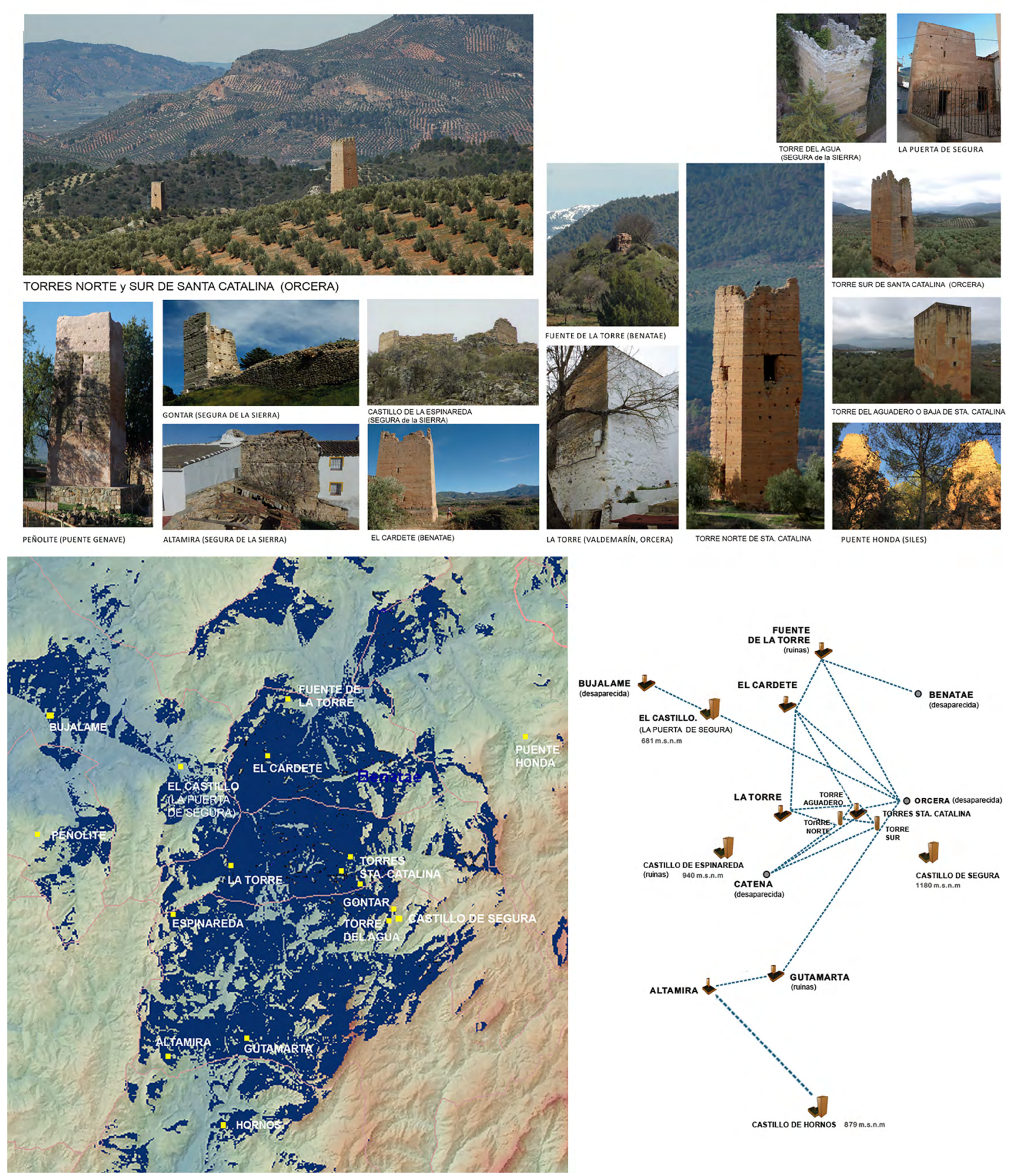

A



Fig. 13. Conjunto de torres del valle de los ríos Trujala, Hornos y Guadalimar. Intervisibilidad en el fondo del valle entre los diferentes asentamientos teniendo en cuenta la altura de las torres. La altura de cada uno de los emplazamientos, junto con la presencia de torres de una altura media de $14 \mathrm{~m}$, elimina los puntos ciegos y permite controlar el $95 \%$ del territorio del valle, existiendo comunicación visual entre centros distantes entre sí. Fuente: elaboración propia.

y Fuente de la Torre (Benatae). Se ha podido comprobar que este patrón se repite también en sitios donde hay documentadas torres desaparecidas, como en Catena ${ }^{69}$, y en lugares que se han transformado en núcleos urbanos como sucede con Torres de Albánchez, Orcera o Benatae. Los

69 Villegas y García, "Relación de los pueblos", pp. 117, 185,228 y 260. emplazamientos en tierras altas tienen un patrón diferente basado en una colonización del terreno con bancales (mảğ $l$ ) y serían: La Hueta o Güeta y Linarejos (Orcera) además de Las Gorgollitas (Santiago-Pontones). Como poblados fortificados estarían Peñolite (Puente Génave) y probablemente Siles. La Puerta de Segura (578,90 m s.n.m.), por la función que desempeñaba de control de acceso al valle desde el noroeste, se ubica 


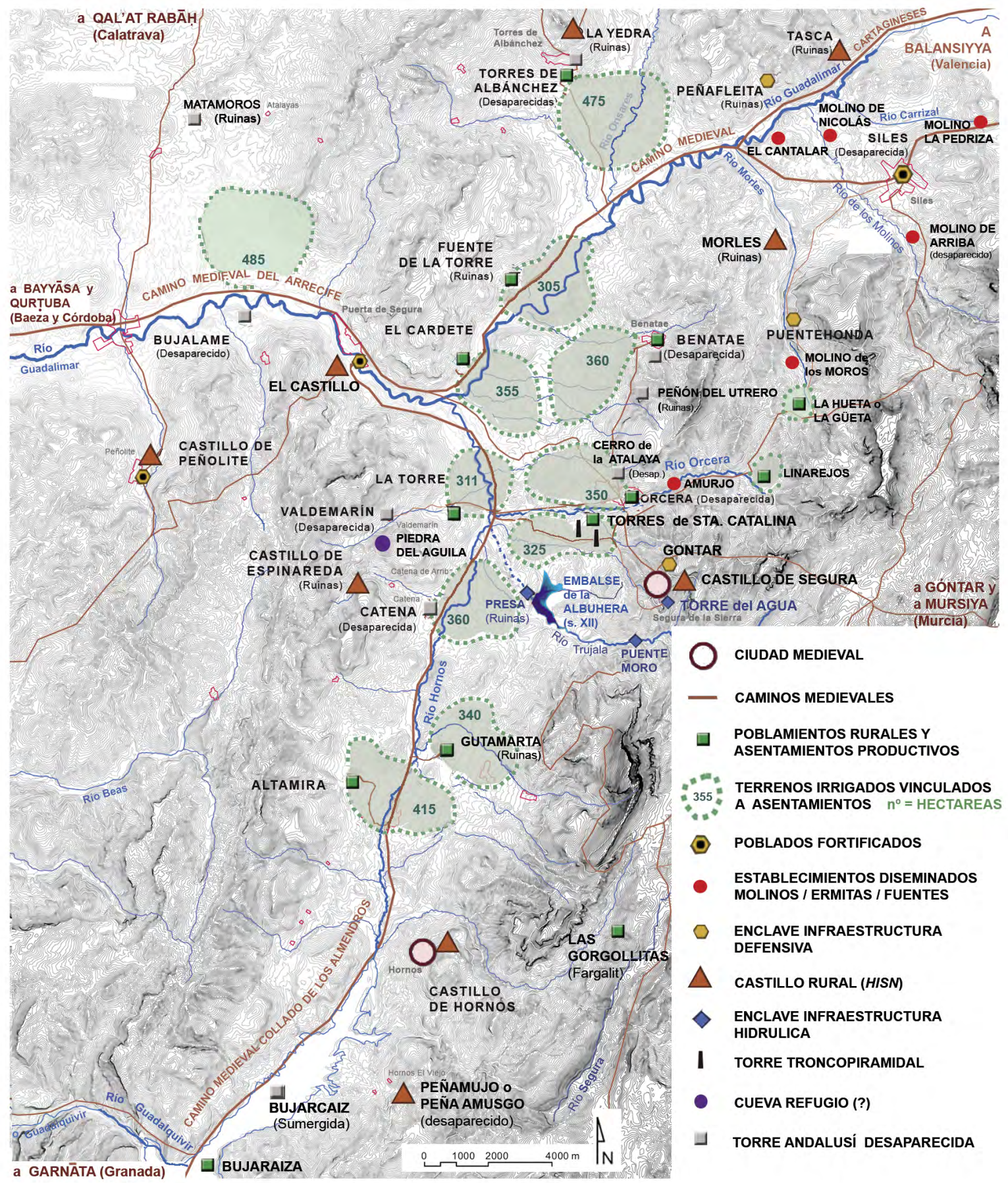

Fig. 14. Cartografía final del paisaje del valle con representación de la red de poblamientos habitacionales, asentamientos productivos, establecimientos diseminados y enclaves de infraestructuras (defensivos, hidráulicos, etc.) y su relación con la orografía, ríos, caminos o terrenos cultivables vinculados a cada uno de los emplazamientos. Fuente: elaboración propia.

junto al río Guadalimar en la cota más baja del valle, siendo una excepción a las pautas encontradas en el resto de asentamientos.

\section{b. Asentamientos rurales productivos}

Serían implantaciones que tenían un carácter agrícola o ganadero, pero no alojarían una comunidad articulada y organizada, sino un grupo de familias dedicadas a labores campesinas. Pertenecerían a este grupo establecimientos agrarios similares a las cortijadas (mağăšir), los rafales (arhal/ riḥāl) o las almunias (munyāt). En Segura, este tipo de asentamiento se coloca en lugares más bajos y llanos que los poblamientos y también posee tierras cultivables vinculadas. Su altitud relativa está cercana al $15 \%$ y su pendiente está en torno 

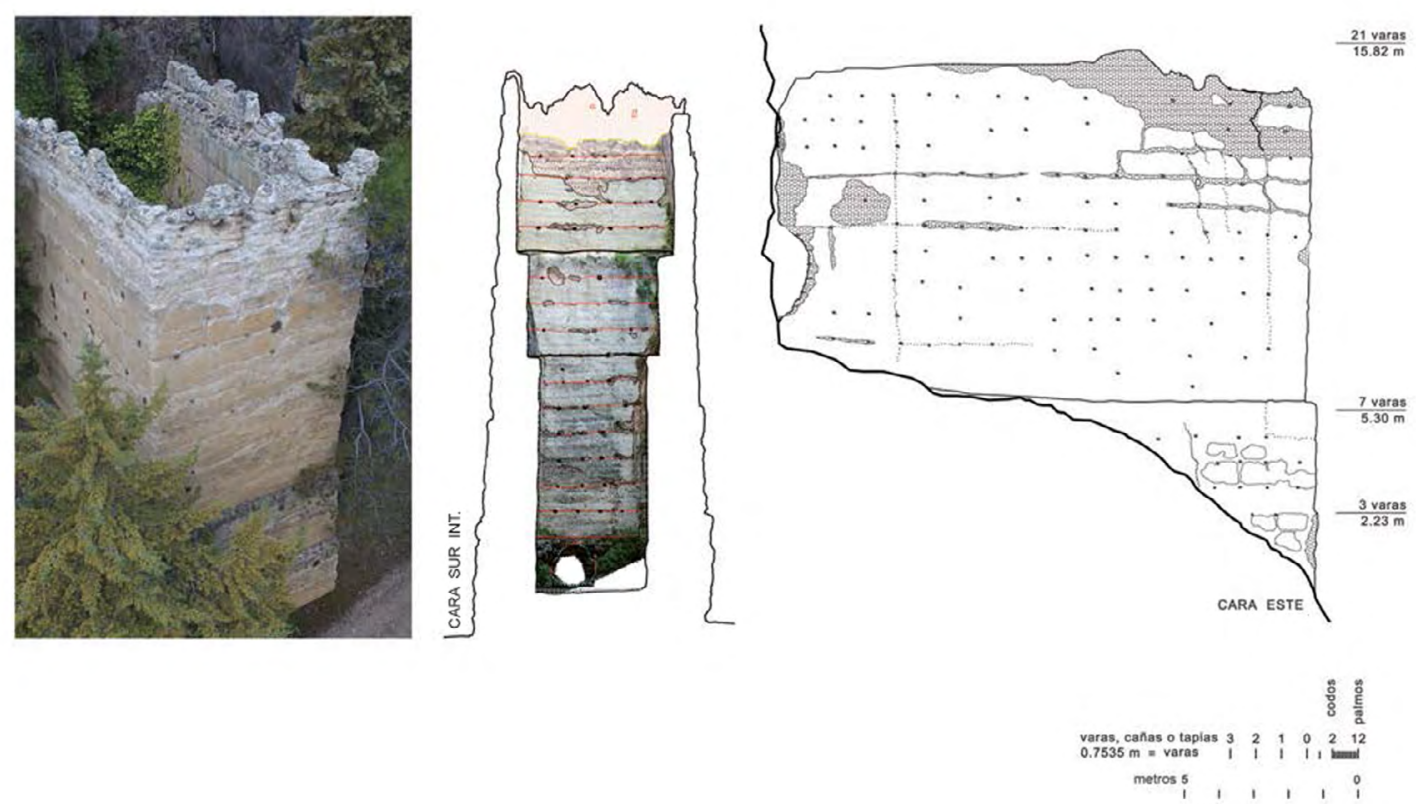

Fig. 15. Torre del Agua (Segura de la Sierra). Una enigmática estructura en forma de U, fuera del recinto amurallado de la ciudad, adosada a la roca y sin ninguna saetera, apertura o acceso, por lo que el ingreso a su interior o la forma en que era usada es una incógnita. Podría haber servido como regulación de agua para el abastecimiento de la ciudad a partir de algún pozo o surgente que pudiera existir en ese lugar. Fuente: elaboración propia.

a los $25^{\circ}$. La distancia media al río más cercano es similar al grupo anterior, rondando los $515 \mathrm{~m}$, igual que la la separación respecto a los acuíferos, cuyo promedio es de $410 \mathrm{~m}$. Pertenecerían a este grupo los yacimientos de la Mesa del Cementerio, el Cerro de la Coja y las tres torres de los llanos de Sta. Catalina (Orcera): Torre del Aguadero, Torre Norte y Torre Sur, ligadas probablemente al sistema de regadío del cercano embalse andalusí de la Albuhera y a la red de caminos pecuarios y de comunicación que pasaban junto a ellas.

\section{c. Establecimientos diseminados}

Serían estructuras dispersas y aisladas con carácter asistencial o productivo. No tienen mucha extensión, como máximo tres, cuatro o cinco edificios. Serían las posadas (manāzil), molinos de trigo (arḥa), graneros (ahrā'), morabitos (murābit). Hay constancia de ermitas en el territorio estudiado, como la de Sta. Catherina o la de Hasmugo, pero no se han encontrado restos. En cambio, se han localizado varios molinos cercanos a ríos o torrentes. La altitud media relativa de estos establecimientos es del $3 \%$ y la pendiente del terreno es muy baja, cercana al $2^{\circ}$, lo que es lógico ya que son asentamientos que no ocupan mucha superficie de terreno. Los establecimientos incluidos en esta categoría serían las ruinas del antiguo molino de Amurjo (Orcera), el Molino de los Moros, además de El Cantalar, La Pedriza y de Nicolás, estos cuatro últimos en el municipio de Siles. Son antiguos molinos de rodezno descritos en las $R e$ laciones de Felipe II, de los que aún se conservan trazas o permanencias en el territorio ${ }^{70}$.

\section{d. Enclaves para infraestructuras}

$\mathrm{Su}$ sentido sería soportar las estructuras y equipamientos necesarios para el funcionamiento de una comunidad. En esta categoría estarían incluidos aquellos emplazamientos destinados a funciones como las defensivas, hidráulicas, fiscales, almacenamiento y control de caminos, entre otras. Los sitios pertenecientes a este grupo son de pequeña extensión, normalmente en lugares escarpados, barrancos o gargantas. No tienen nunca espacios cultivables cercanos. Debido a sus dimensiones o a las condiciones del entorno no estarían necesariamente habitados permanentemente. La distancia media a los acuíferos está entre 220 y $500 \mathrm{~m}$. Corresponderían a esta categoría los siguientes tipos: castillos rurales (hușūn), peñas fortificadas (sahrāt), fortines (ma'āqil), fortalezas ( $q i l \bar{a})$, atalayas (talāyi ), silos (mațāmir), azudes (asd $\bar{a} d)$, norias (nawā $\bar{\imath} r$ ), puentes (qanātir) o las cuevas-granero. En la zona de estudio, los enclaves de infraestructura con utilidad defensiva serían: Espinareda y Góntar (Segura de la Sierra), Cerro de la Atalaya y Peñón de Utre-

\footnotetext{
70 Vigueras, "Los molinos de Rodezno", pp. 105-121.
} 

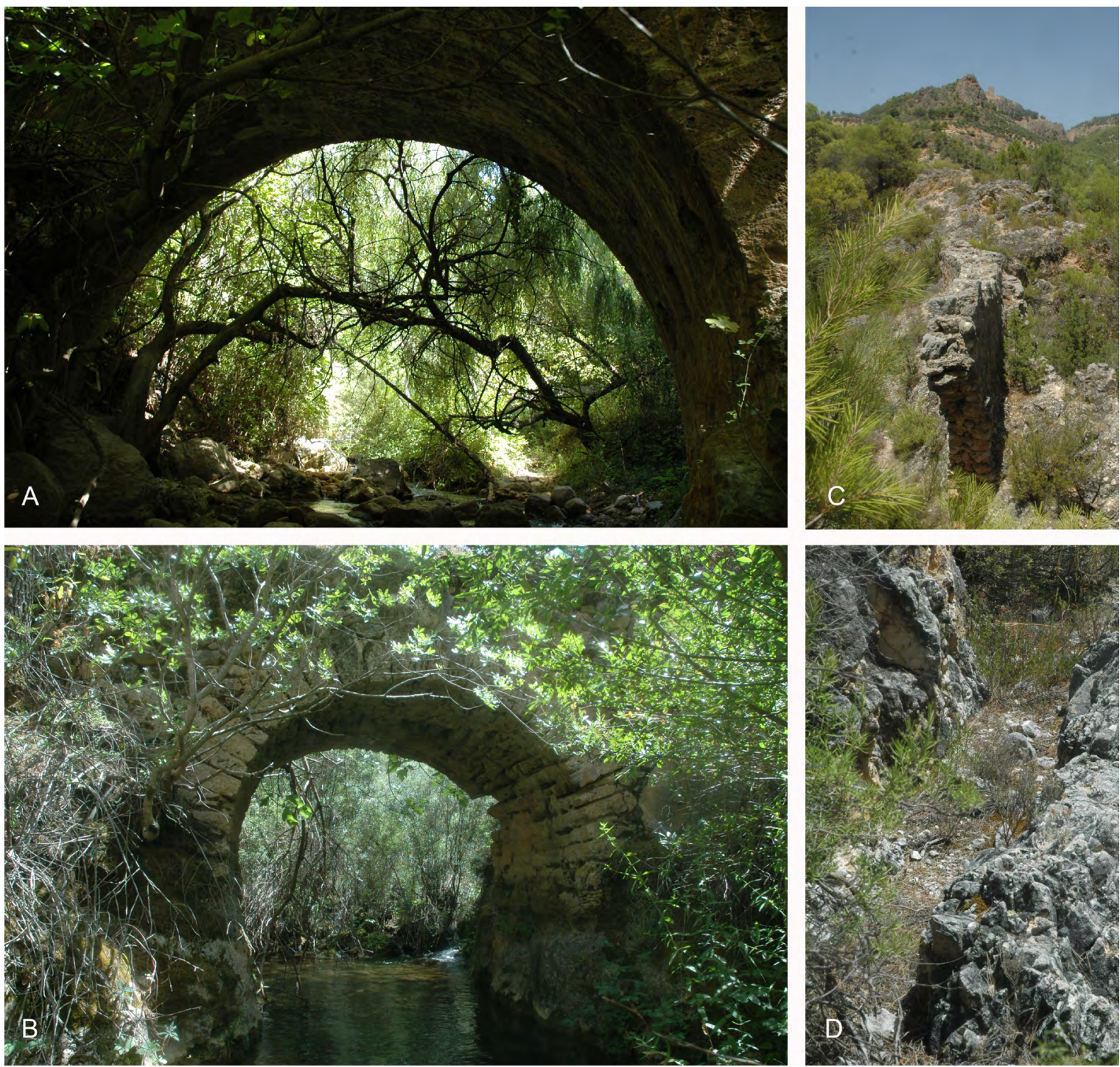

Fig. 16. A/ Puente Moro B/ Puente Romillán C/ Acueducto Romillán para la conducción de una acequia; al fondo, el castillo de Segura de la Sierra D/ Acequia tallada en roca en su trazado previo a la acometida al acueducto.

ro (Orcera), la Torrecilla y la Yedra (Torres de Albanchez), Morles, Puente Honda, Tasca y Peñafleita (Siles). En estos lugares la pendiente del terreno alcanza magnitudes mayores a los $40^{\circ}$ y su altitud relativa está por encima del $85 \%$. Entre los enclaves destinados a infraestructura hidráulica estarían la Torre del Agua (Figura 15), la presa del embalse de la Albuhera, el Puente Moro, el puente de Romillán y los cercanos restos de un acueducto que conduce una acequia (Figura 16), todos ellos en el término de Segura de la Sierra.

\section{Conclusiones}

Esta investigación sobre los asentamientos andalusíes de la Sierra de Segura ha aplicado un modelo de evaluación en entorno SIG que extrae información del paisaje y cuantifica algunas de sus variables con parámetros contrastables. Un procedimiento con el que se obtiene un conocimiento que proporciona una mejor comprensión de la distribución y diferentes formas de ocupación de estos establecimientos rurales, permitiendo clasificarlos con criterios territoriales y profundizar en aspectos poco conocidos de los mismos que otras caracterizaciones de tipo documental, arqueológico, fiscal o terminológico no acaban de revelar. La primera conclusión que se extrae del trabajo realizado es que no se puede considerar que la situación de los asentamientos en la amelía de Segura hubiera estado condicionada por esta ciudad o que los emplazamientos hayan sido espacios residuales ubicados en territorios marginales entre los intersticios de ciuda- 
des, como pudiera ocurrir en otros lugares de la Península Ibérica ${ }^{71}$. Tampoco se reconoce una relación de dependencia directa entre husșūn y posibles qurà u otro tipo de sitios productivos o residenciales, como apuntaba el modelo propuesto por investigadores franceses en la década de los ochenta ${ }^{72}$.

Uno de los principales hallazgos de esta investigación ha sido constatar que los establecimientos habitacionales o productivos siguen algunas pautas comunes. Su emplazamiento está estrechamente relacionado con la red fluvial, los acuíferos y los caminos; está ubicado en un lugar con una altitud relativa baja, pero siempre por encima del terreno de laboreo y de las superficies susceptibles de inundación. La tierra disponible para cultivar y la capacidad de irrigación son las variables que determinan la instalación del asentamiento habitacional. En los lugares más escarpados y abruptos, el elemento condicionante es la hidráulica y la línea de rigidez que marca el recorrido desde la captación de agua. En estos casos, el terreno para el trabajo agrícola es un espacio configurado por terrazas en bancales. En el fondo del valle, en terrenos ondulados y suaves donde la captación y el recorrido del agua son menos problemáticos, no hay bancales y los asentamientos están condicionados por la extensión disponible de tierras de labor. Este patrón repetitivo lleva a la conclusión de que la elección de los emplazamientos rurales, durante la colonización de las comarcas de Segura, fue debida a la presencia de terrenos cultivables irrigados y no tanto a motivos defensivos, políticos o administrativos.

Esa forma de asentamiento confirmaría también en este territorio la correspondencia entre espacios agrarios y organización social andalusí, advertida por diversos autores en otras regiones de al-Andalus, por la cual la población campesina se habría agrupado en el medio rural en determinados puntos, explotando el territorio en función de la disponibilidad de recursos y terrenos aptos para ser labrados ${ }^{73}$. Se trata de

71 Azuar, "Castillos y espacios marginales", pp. 89-108.

72 Bazzana, Cressier y Guichard, Les châteaux.

73 Tal y como Cressier adelantó en sus trabajos sobre la Alpujarra. Cressier, "Agua, fortificaciones y poblamiento", pp. 403-428. También como Barceló, Kirchner y Navarro han demostrado en sus diferentes estudios sobre los espacios hidráulicos andalusíes. Barceló, "Sistemas de irrigacion", pp. 59-71; Barceló, "Diseño de espacios”, pp. 2013-2047; Kirchner, "Redes de asentamientos", pp. 79-94; Navarro, "Fortificaciones y asentamientos", pp. 205-231. un patrón de implantación que, generalmente, se ha asociado a espacios irrigados construidos con la llegada a al-Andalus de grupos de beréberes. No obstante, en las comarcas de Segura de lo que hay noticias es del establecimiento de tribus árabes y yemeníes. Guichard y Cressier han apreciado raíces comunes, beréberes y árabes, en los mecanismos sociales de distribución del agua por lo que, en principio al menos en lo que se refiere a la explotación de la tierra, cabría admitir en ambos grupos étnicos una forma parecida de comportamiento frente a problemas similares. En las comarcas de Segura se podría haber producido una colonización agrícola de ambas poblaciones. Una repoblación temprana a partir del siglo VIII de las tierras altas por parte de yemeníes, y otra más tardía a partir del siglo XI por tribus beréberes que se asentarían en los valles y tierras bajas de la Sierra de Segura.

El modelo de ocupación del territorio hacia el que apunta esta investigación para su desarrollo en futuros trabajos es que estos asentamientos rurales no habrían funcionado de forma jerárquica en torno a las mudun o los hușūn, sino que serían nodos de un articulado y complejo sistema territorial, conectado con otras comarcas y territorios de al-Andalus a través de redes fluviales y de transporte terrestre. Estos núcleos no urbanos tendrían diferente repercusión en el territorio, una cierta autonomía y capacidad de interactuar entre sí. Sería un tipo de organización en red con diversos gradientes de utilización en función de las necesidades espaciales y temporales a las que pudieran estar sometidos en cada momento. Los poblamientos rurales agrícolas, una vez fundados y habitados por grupos tribales yemeníes o beréberes, habrían sido aprovechados por otros agentes, bien locales o estatales, para, una vez comprobada su utilidad en función de su posición o peso en el territorio, controlar estos nodos con el fin de construir en ellos infraestructuras, explotaciones agropecuarias, baluartes, torres o recaudar impuestos. Actuaciones que, en definitiva, formarían parte de un programa edificatorio, fiscal o representativo de implantación en el territorio que complementaría los núcleos, previamente existentes, ubicados en cotas menos accesibles y peor comunicadas. Se trata de una realidad no desvelada todavía pero que es posible abordar desde diferentes perspectivas como el análisis descriptivo del paisaje expuesto aquí. Es, en fin, un acercamiento, limitado, concreto y siempre 
parcial, que ha servido para descubrir aspectos todavía desconocidos del bello paisaje que definen estos asentamientos humanos en estrecha relación con la naturaleza.

\section{Agradecimientos}

Agradezco la colaboración de Guadalupe Romero-Vergara y Noemí Serrano Garrido en la elaboración de algunos mapas que ilustran este artículo. Por último, mi sincero reconocimiento a las sugerencias, comentarios y aportaciones de los revisores anónimos con los que ha crecido enormemente el manuscrito original y se ha beneficiado el texto final.

\section{Bibliografía}

Acién Almansa, Manuel, "De nuevo sobre la fortificación en el emirato", en Isabel Cristina Ferreira Fernandes (coord.), Mil anos de fortificações na Península Ibérica e no Magreb (500-1500), Lisboa, Edições Colibrí y Câmara Municipal de Palmela, 2002, pp. 59-75.

Aguirre Sádaba, Francisco Javier y Jiménez Mata, María del Carmen, Introducción al Jaén islámico (Estudio geográfico-histórico), Jaén, Instituto de Estudios Giennenses, 1979.

Almagro Gorbea, Antonio, Orihuela Uzal, Antonio y Vílchez Vílchez, Carlos, "La puerta de Elvira en Granada y su reciente restauración", Al-Qantara, 13, 2 (1992), pp. 505-536.

Azuar Ruiz, Rafael, "Castillos y espacios marginales de las ciudades en el Sarq al-Andalus (siglos XI-XIII)", en Patrice Cressier (ed.), Castrum 8. Le château et la ville. Espaces et réseaux (VI $\mathrm{e}-X I I^{\mathrm{e}}$ siècle), Madrid, Casa de Velázquez, 2008, pp. 89-108.

Azuar Ruiz, Rafael, Lozano, Francisco José, Llopis, Teresa María y Menéndez, José Luis, "El falso despiece de sillería en las fortificaciones de tapial de época almohade en al-Andalus", Estudios de Historia y Arqueología Medievales, 6 (1996), pp. 245-278.

Barceló, Miquel, "Sistema de irrigación y asentamientos en los términos de Huesa; Belerda; Tíscar-Don Pedro y Cuenca (Jaén)", en AA.VV., Anuario Arqueológico de Andalucía (actividades sistemáticas), Sevilla, Junta de Andalucía, 1988, t. II, pp. 59-71.

Barceló, Miquel, "El diseño de espacios irrigados en alAndalus: Un enunciado de principios generales", en Lorenzo Cara Barrionuevo (coord.), El agua en zonas áridas. Arqueología e Historia. Hidráulica tradicional en la provincia de Almería, Almería, Instituto de Estudios Almerienses, 1989, pp. 2013-2047.
Barker, Graeme,"L'archeologia del paesaggio italiano: nuovi orientamenti e recenti esperienze", Archeologia Medievale, 13 (1986), pp. 7-30.

Bazzana, André, Cressier, Patrice y Guichard, Pierre, Les châteaux ruraux d'al-Andalus. Histoire et archéologie des husun du sud-est de l'Espagne, Madrid, Casa de Velázquez, 1988.

Bellón Ruiz, Juan Pedro, Rueda Galán, Carmen y Sánchez Justicia, Beatriz, "Prospección arqueológica superficial en el entorno de las torres de Santa Catalina (Orcera, Jaén)", en AA.VV., Anuario Arqueológico de Andalucía 2004.2, Sevilla, Junta de Andalucía, 2004, pp. 572-581.

Bolens, Lucie, "La révolution agricole andalouse du XI' siècle", Studia Islamica, 47 (1978), pp. 121-141.

Caniggia, Gianfranco, Strutture dello spazio antropico, Florencia, Alinea, 1975.

Canto de Gregorio, Alicia, "Ilorci, Scipionis rogus (Plinio, NH III, 9) y algunos problemas de la Segunda Guerra Púnica en Hispania", Rivista Storica dell'Antichità, 29 (1999), pp. 154-157.

Carrión García, José Sebastián, "Pastoreo y vulnerabilidad de la vegetación en la alta montaña mediterránea durante el Holoceno", Cuadernos de Geografía, 69-90 (2001), pp. 7-22.

Crespo García, José María y Pérez Bareas, Cristóbal, "Prospecciones arqueológicas superficiales en el término municipal de Orcera", en AA.VV., Anuario Arqueológico de Andalucía (actividades de urgencia), Sevilla, Junta de Andalucía, 1987, t. III, pp. 329-337.

Cressier, Patrice, “Agua, fortificaciones y poblamiento. El aporte de la arqueología a los estudios sobre el Sureste peninsular", Aragón en la Edad Media, 9 (1991), pp. 403-428.

Cruz Aguilar, Emilio de la, "El reino Taifa de Segura", Boletín del Instituto de Estudios Giennenses, 153, 2 (1994), pp. 883-914.

Cruz Aguilar, Emilio de la, “¿Otra vía romana entre Cástulo y Cartagena?", Revista de la Facultad de Derecho de la Universidad Complutense, 16 (1990), pp. 35-44.

Fagnan, Edmon, Extraits inédits relatifs au Maghreb (Géographie et Historie) traduits de l'arabe et annotés, Argel, Jules Carbonel, 1924.

Fajri al-Wasif, Muhammad, "La inmigración de árabes yemeníes a al-Andalus desde la conquista islámica (92/711) hasta finales del siglo II/VIII", Anaquel de Estudios Árabes, 1 (1990), pp. 203-219.

Frey Sánchez, Antonio Vicente, “La percepción del territorio murciano y su medio natural por los geógrafos árabes en la Edad Media (I). Desde la invasión hasta el dominio almorávide", Murgetana, 136 (2017), pp. 9-35. 
Glick, Thomas, Paisajes de conquista. Cambio cultural y geográfico en la España medieval, Valencia, Universidad de Valencia, 2007.

Guichard, Pierre, "Le problème des structures agraires en al-Andalus avant la conquête chrétienne", en Emilio Cabrera Muñoz (coord.), Andalucía entre Oriente y Occidente (1236-1492). Actas del V Coloquio Internacional de Historia Medieval de Andalucía, Córdoba, Diputación Provincial de Córdoba, 1988, pp. 161-170.

al-Hiimyarī, Abū 'Abd Allāh Muḥammad b. 'Abd al Mun 'im, Kitab al-rawd al-mi'tar, M. Pilar Maestro González (trad.), Valencia, [s.n.], 1963.

Huici Miranda, Ambrosio, Historia política del Imperio Almohade, 2 vols., Granada, Universidad de Granada, 2000.

Ibn Luyūn, Kitāb al-Filāha: Tratado de Agricultura, Joaquina Eguaras Ibáñez (trad. y estudio), Almería, Universidad de Almería, 2014.

al-Idrīsī, Muḥammad b. Muḥammad al-Šarīf, Uns al-muhağ wa-rawd al-furağ. Los caminos de alAndalus en el siglo XII, según "Uns al-muhaŷ warawd al-furaŷ" (Solaz de corazones y prados de contemplación), Jassim Abid Mizal (ed. y trad.), Madrid, CSIC, 1989.

Kirchner, Helena, "Redes de asentamientos andalusíes y espacios irrigados a partir de qanât(s) en la sierra de Tramuntana de Mallorca: una reconsideración de la construcción del espacio campesino en Mayûrca", en Helena Kirchner (ed.), Por una arqueología agraria; perspectivas de investigación sobre espacios de cultivo en las sociedades medievales hispánicas, Oxford, BAR International, 2010, pp. 79-94.

Kirchner, Helena y Navarro Romero, Carmen, “Objetivos, métodos y prácticas de la arqueología hidráulica”, Arqueología y Territorio Medieval, 1 (1994), pp. 159-182.

Lombard, Maurice, "Un problème cartographié: Le bois dans la Mediterranée musulmane (VII ${ }^{\mathrm{e}} \mathrm{XI}^{\mathrm{e}}$ siècles)", Annales. Économies, Sociétés, Civilisations. 14 e année, 2 (1959), pp. 234-254.

López Elum, Pedro, La alquería islámica en Valencia. Estudio arqueológico de Bofilla, siglos XI-XIV, Valencia, Pedro López Elum, 1994.

Malpica Cuello, Antonio, "El paisaje del mundo rural andalusí. Bases descriptivas para su análisis”, $P H$ : Boletín del Instituto Andaluz del Patrimonio Histórico, 27 (1999), pp. 146-153.

Martínez Enamorado, Virgilio, Al-Andalus desde la periferia. La formación de una sociedad musulmana en tierras malagueñas (siglos VII-X), Málaga, Centro de Ediciones de la Diputación Provincial de Málaga, 2003.
Muratori, Saverio, Civiltà e Territorio, Roma, Centro di studi di storia urbanistica, 1967.

Navarro Romero, Carmen, "El tamaño de los sistemas hidráulicos de origen andalusí: la documentación escrita y la arqueología hidráulica", en Lorenzo Cara Barrionuevo y Antonio Malpica Cuello (coords.), Agricultura y regadio en al-Andalus. Síntesis y problemas. II Coloquio de Historia y Medio Físico, Almería, Instituto de Estudios Almerienses,1995, pp. 177-189.

Navarro Romero, Carmen, "Fortificaciones y asentamientos andalusíes en la actual provincia de Albacete: un alAndalus textualmente casi invisible", en Pierre Toubert y Miquel Barceló (eds.), L'incastellamento. Actes des rencontres de Gérone (26-27 novembre 1992) et de Rome (5-7 mai 1994), Rome, École Française de Rome, 1998, pp. 205-231.

Oliver Asín, Jaime, "En torno a los orígenes de Castilla: su toponimia en relación con los árabes y los beréberes", Al-Andalus, 38, 2 (1973), pp. 319-391.

Pérez Aguilar, Luis Gethsemaní, "Problemas metodológicos en el estudio del mundo rural andalusí", Mediavalista, 14 (2013), [en línea], disponible en: $<$ https://doi.org/10.4000/medievalista.398>.

Piqueras Haba, Juan y Fansa, Ghaleb, "La Península Ibérica en el gran Atlas de al-Idrīsī”, Treballs de la Societat Catalana de Geografia, 65 (2008), pp. 465-477.

Pocklington, Robert, "Toponimia ibérica, latina y árabe de la provincia de Albacete", Al-Basit, Revista de Estudios Albacetenses, 55 (2010), pp. 111-167.

Quesada-García, Santiago y Romero-Vergara, Guadalupe, "El sistema de torres musulmanas en tapial de la Sierra de Segura (Jaén): Una contribución al estudio del mundo rural y el paisaje de al-Andalus", Arqueología de la Arquitectura, 16 (2019), e079, [en línea], disponible en: <https://doi.org/10.3989/ arq.arqt.2019.001>.

Quesada-García, Santiago, El sistema de torres musulmanas de la Sierra de Segura. Una contribución al paisaje y patrimonio rural de al-Andalus. \#ProyectoSegura, Sevilla, HAC university books, 2019.

Quesada Quesada, Tomás, "El poblamiento medieval en las sierras subbéticas de Jaén y Granada. El caso de Sierra Mágina", Studia Historica. Historia Medieval, 9 (1991), pp. 159-182.

Retamero Serralvo, Félix, "Irrigated agriculture, risk and population. The Andalusi hydraulic system of the Balearic Islands as a case study (Xth-XIIIth century)", en Rita Compatangelo-Soussignan, JeanRené Bertrand y Pierre-Yves Laffont (eds.), Marqueurs des paysages et systèmes socio-économiques, Rennes, Presses Universitaires de Rennes, 2007, pp. 135-147.

Rueda Galán, Carmen y Bellón Ruiz, Pedro, "Culto y rito en cuevas: modelos territoriales de vivencia y experimentación de lo sagrado, más allá de la 
materialidad (ss. V-II a.n.e.)", ARYS, 14 (2016), pp. 43-80.

Salvatierra Cuenca, Vicente y Visedo Jiménez, Ana, "Segura de la Sierra y el origen de la articulación de un territorio medieval", en Patrice Cressier (ed.), Castrum 8. Le château et la ville. Espaces et réseaux (VI ${ }^{e}$-XIII ${ }^{e}$ siècle), Madrid, Casa de Velázquez, 2008, pp. 135-150.

Terés Sábada, Elías, "Linajes árabes en al-Andalus (primera parte)", Al-Andalus, 22, 1 (1957), pp. 55-111.

Terés Sábada, Elías, "Linajes árabes en al-Andalus según la 'Yamhara' de Ibn Hazm (conclusión)", Al-Andalus, 22, 2 (1957), pp. 337-376.

Torres Balbás, Leopoldo, Ciudades hispano-musulmanas, Madrid, Dirección General de Relaciones Culturales e Instituto Hispano-Árabe de Cultura, 1985.

Vallvé Bermejo, Joaquín, "La división territorial en la España musulmana. La cora de Jaén", Al-Andalus, 24, 1 (1969), pp. 55-82.

Vallvé Bermejo, Joaquín, "Notas de metrología hispanoárabe. El codo en la España Musulmana", Al-Andalus, 41, 2 (1976), pp. 339-354.
Vallvé Bermejo, Joaquín, La división territorial en la España musulmana, Madrid, CSIC, 1986.

Vidal-Castro, Francisco, "Šaqūra (Segura de la Sierra) en la historia y cultura de al-Andalus", en Guillermo Fernández Rojano (coord.), Segura de la Sierra, territorio de frontera, Segura de la Sierra, Fundación Patrimonio Sierra de Segura, 2009, pp. 8-25.

Viguera Molins, María Jesús, "La organización militar en al-Andalus", Revista de Historia Militar, núm. extra. 1 (2001), pp. 17-60.

Vigueras González, Modesto, "Los molinos de Rodezno de Siles, Sierra de Segura (Jaén)", en AA.VV., I Jornadas Nacionales sobre Molinología, Santiago de Compostela, Edicións do Castro, 1997, pp. 105-121.

Villegas Díaz, Luis Rafael y García Serrano, Rafael, "Relación de los pueblos de Jaén, ordenadas por Felipe II", Boletin del Instituto de Estudios Giennenses, 88-89 (1976), pp. 9-304.

Zanón, Jesús, "Un itinerario de Córdoba a Zaragoza en el siglo X", Al-Andalus, 7, 1-2 (1986), pp. 31-52.

al-Zuhrī, Abū 'Abd Allāh Muḥammad ibn Abī Bakr, Kitāb alĞa 'rāfiyya. Libro de Geografia, Mahammad Hadj-Sadok (ed.), Bulletin d'études orientales, 21 (1968), pp. 7-312. 